\title{
Wellness and the Role of Comorbidities in Multiple Sclerosis
}

\author{
Brandon P. Moss ${ }^{1} \cdot$ Mary R. Rensel $^{1} \cdot$ Carrie M. Hersh $^{2}$
}

Published online: 7 August 2017

(C) The American Society for Experimental NeuroTherapeutics, Inc. 2017

\begin{abstract}
Multiple sclerosis (MS) is a demyelinating and neurodegenerative disorder of the central nervous system, for which disease modifying therapies (DMTs) are the mainstay treatment approach to reduce inflammatory disease activity and slow worsening disability. In addition to conventional pharmacologic therapy, there is growing interest in the use of lifestyle strategies to support wellness and mitigate disease-related complications in MS. This interest stems from a growing appreciation of the role of certain comorbidities and lifestyle factors on disease activity, disability, mortality, and overall quality of life. While the current literature is not conclusive, there is evidence to suggest a potential role for vitamin D supplementation, tobacco smoking cessation, routine exercise, a plant-based, anti-inflammatory diet, and maintenance of emotional well-being as adjunct therapies to DMTs. In addition to DMTs, lifestyle strategies should be emphasized as part of a management plan focused on overall health and well-being.
\end{abstract}

Keywords Wellness $\cdot$ Lifestyle medicine $\cdot$ Obesity $\cdot$ Vascular comorbidities $\cdot$ Psychiatric comorbidities $\cdot$ Multiple sclerosis

Brandon P. Moss

mossb@ccf.org

1 Mellen Center for Multiple Sclerosis Treatment and Research, Cleveland Clinic, Cleveland, OH, USA

2 Lou Ruvo Center for Brain Health, Cleveland Clinic, Las Vegas, NV, USA

\section{Introduction}

Multiple sclerosis (MS) is an inflammatory demyelinating and neurodegenerative disease of the central nervous system affecting approximately 400,000 people in the USA [1] and 2.5 million people worldwide [2]. It is the major cause of nontraumatic neurologic disability in young adults $[3,4]$, and, compared with other chronic conditions, MS ranks second only behind congestive heart failure in direct all-cause medical costs, with an estimated cost of $\$ 8528$ to $\$ 54,244$ per patient with MS per year [5].

There is growing interest in the impact of comorbidities on disease-related outcomes in MS and its effect on increasing healthcare costs. Although definitions can vary, comorbidity typically refers to coexisting disease states other than the condition of interest and is distinct from complications of the prespecified disease [6]. An increasing amount of evidence suggests that comorbidities can affect diagnostic delay, worsening disability, health-related quality of life (HRQoL), and risk of hospitalization [7-11]. In addition, comorbid diseases add significant societal costs to the management of a chronic progressive illness. Approximately $80 \%$ of US Medicare spending is devoted to people with 4 or more chronic conditions with costs increasing exponentially as the number of comorbidities increases [12].

These comorbidities and their impact on disease-related outcomes in MS may be amenable to changes in lifestyle. The study of lifestyle medicine, defined as the integration of lifestyle practices into the practice of medicine [13], has grown out of an understanding of the importance of patient behavior in health and wellness. These lifestyle practices, including diet, physical activity, weight control, maintenance of emotional well-being, and tobacco cessation, are aimed at lowering the risk of developing chronic diseases and serve as an adjunct treatment for chronic diseases already present. 
They are meant to complement and not replace conventional therapies in MS, namely disease modifying therapies (DMTs) that reduce inflammatory disease activity and slow worsening of disability. Incorporation of lifestyle medicine into traditional medical care is part of a growing trend towards integrative medicine. Integrative medicine focuses on wellness, a holistic concept of well-being, that encompasses biological, psychological, sociological, and spiritual aspects of overall health within the framework of a strong patient-physician relationship $[14,15]$.

In this paper, we first discuss the growing evidence for the impact of comorbidity and lifestyle factors on outcomes in MS, and then discuss how lifestyle strategies may impact these outcomes. The focus of the paper is on lifestyle strategies that mitigate disease activity, worsening disability, or chronic symptoms, and affect quality of life in MS. The role of lifestyle strategies in reducing the risk of MS is an important issue but beyond the scope of this paper. For all topics, we focused on higher quality summaries of the literature found within recent published systematic reviews. Representative papers from the literature were also chosen where systematic reviews were unavailable or did not capture all of the pertinent studies.

\section{Comorbidities}

\section{Obesity}

Impact of Obesity on the Immune System

The key cell of adipose tissue is the adipocyte, which secretes a variety of hormones, including leptin, adiponectin, and resistin to help regulate satiety, insulin resistance, and inflammation [16]. Under conditions of obesity, however, adipocytes secrete many proinflammatory cytokines, including tumor necrosis factor- $\alpha$, monocyte chemoattractant protein 1 , and interleukin (IL)-6 [17]. Both leptin and IL-6 reduce regulatory T-cell activity $[18,19]$, and higher leptin levels are associated with fewer circulating regulatory $\mathrm{T}$ cells in the peripheral blood [20], suggesting a possible connection between obesity and immune system dysfunction.

\section{Prevalence of Obesity}

Most of the literature on obesity prevalence is based on survey data. The largest survey, conducted in 2006, included 8983 responders with a $55.7 \%$ response rate. Participants were selected from the North American Research Committee on MS (NARCOMS) Registry, a self-report registry for people with MS. In this survey, a quarter of participants were obese, and close to one-third were overweight [21]. Pilutti et al. [22] conducted a smaller survey with 269 participants where $>$
$50 \%$ of participants were classified as overweight or obese. Only people able to walk independently or with a cane were included in the survey, raising the possibility that the results might be an underestimation of the true prevalence of obesity in the MS population at large. Moreover, both studies used self-reported data, a potential limitation because survey responders who are overweight are more likely to under-report their correct weight [23]. Finally, a cross-sectional study of 130 patients with MS with a Kurtzke Expanded Disability Status Scale $(E D S S) \geq 3.0$ used data from the Sheba MS Registry, a large university-affiliated medical center database in Tel Aviv, Israel [24]. In total, $18.5 \%$ of disabled patients with MS were obese, and $34.6 \%$ were overweight.

A 2013 systematic review of risk factors related to cardiovascular disease and metabolic syndrome in MS found conflicting data on body mass index (BMI) in MS populations versus the general public [25]. Some studies found the proportion of overweight and obese people with MS were comparable with the general population $[26,27]$. Other studies reported a higher prevalence of obesity in women and veterans with MS [28-32]. Other studies found a lower prevalence of obesity in people with MS than in controls [33-35].

\section{Impact of Obesity on MS Disease Activity and Worsening of Disability}

Two prospective cohort studies investigated the association of obesity with disease activity in MS. The first enrolled 86 subjects from participants in the OFAMS study, a randomized, double-blind, placebo-controlled trial of omega- 3 fatty acids in Norwegian people with relapsing remitting MS (RRMS) [36]. During interferon- $\beta$ (IFN- $\beta$ ) treatment, overweight and obese patients had higher disease activity than normal-weight participants when evaluated by the criterion of "no evidence of disease activity," a composite measure of magnetic resonance imaging (MRI) evidence of disease activity, clinical relapses, and worsening disability. This association was only seen during treatment with IFN $-\beta$ and was related primarily to the MRI and clinical relapse components of no evidence of disease activity. The second cohort study followed 141 participants with RRMS from 2002 to 2005, selected from a cohort of 203 people with MS living in southern Tasmania, Australia [37]. BMI was measured at baseline and was not found to be associated with the risk of relapse [hazard ratio (HR) 1.02, 95\% confidence interval (CI) 0.98-1.07]. A similar prospective study, using the same cohort, described the association between BMI and disability [38]. In this study, there was a direct relationship between BMI and disability such that participants with a $5 \mathrm{~kg} / \mathrm{m}^{2}$ higher BMI score had, on average, a 0.38 higher EDSS score $(p=0.013)$. Associations with disability were adjusted for important confounders, including relapse at the time of disability assessment, age at study entry, 
sex, smoking, statin use, physical activity, 25-hydroxyvitamin $\mathrm{D}[25(\mathrm{OH}) \mathrm{D}]$, and baseline EDSS.

The studies used to describe the prevalence of obesity in MS were also used to evaluate the association between BMI and disability worsening. In the NARCOMS survey, participants were grouped into mild $(n=1318)$, moderate $(n=350)$, and severe $(n=707)$ disability based on the Patient Determined Disease Steps (PDDS), a self-report disability scale validated against the EDSS [39]. Compared with participants with mild disability, those with moderate disability did not have increased odds of being overweight [odds ratio (OR) $0.99,95 \%$ CI $0.82-1.18]$ or obese (OR $1.09,95 \%$ CI 0.90 1.33). Moreover, after accounting for smoking status and physical activity level, participants with severe disability had decreased odds of being overweight (OR $0.67,95 \%$ CI 0.55 0.82 ) or obese (OR $0.71,95 \%$ CI $0.58-0.87$ ) [21]. In the survey conducted by Pilutti et al. [22], the relationship between the PDDS and BMI was analyzed over time using a panel model framework. There were no significant correlations between BMI and PDDS at baseline, 12 months, or 24 months $(p>0.05)$. Path analysis indicated a minimal and inconsistent impact of BMI on the change in PDDS over time. Finally, the cross-sectional study of patients from the Sheba MS Registry found no significant differences among the normal weight, overweight, and obese groups with respect to EDSS scores $(p=0.192)$ [24].

Overall, there is insufficient evidence to support a strong association between weight status and disability. This may be, in part, due to poor sensitivity of the current measures for overweight and obesity. Although most of the studies evaluating obesity in people with MS have used a cut-off BMI value $\geq 30 \mathrm{~kg} / \mathrm{m}^{2}$, at least 1 study suggests that the current threshold for classifying obesity may be too high [40]. The investigators conducted a secondary analysis of crosssectional data to examine the relationship between BMI and percentage body fat assessed by dual-energy X-ray absorptiometry in a large sample of participants with and without MS. Receiver operating characteristic curve analyses indicated that the standard BMI threshold for obesity had excellent specificity (93-100\%) but poor sensitivity (37-44\%) in both persons with MS and non-MS controls. The BMI threshold that best identified percentage-body-fat-defined obesity was $24.7 \mathrm{~kg} /$ $\mathrm{m}^{2}$ in the MS group and $25.1 \mathrm{~kg} / \mathrm{m}^{2}$ in the control group.

\section{Vascular Comorbidities}

\section{Prevalence of Vascular Comorbidities}

A 2015 systematic review analyzed the incidence and prevalence of type II diabetes (DM type II), hyperlipidemia (HPL), hypertension (HTN), coronary artery disease (CAD), cerebrovascular disease, and peripheral vascular disease (PVD) in individuals with MS [41]. For most of these comorbidities, the estimates varied widely, as did the quality of the studies. Furthermore, there were inconsistent findings comparing the prevalence of these comorbidities in MS populations with their respective controls or to published data in the general population. One exception was ischemic heart disease, in which all 14 studies found elevated incident rate ratios (IRRs) in their MS populations versus matched controls. Table 1 includes a detailed list of the prevalence estimates for DM type II, HPL, HTN, CAD, cerebrovascular disease, and PVD in the MS population.

\section{Impact of Vascular Comorbidities on MS Disease Activity and Worsening of Disability}

Two studies found an association between vascular comorbidities and T2 lesion burden. One prospective longitudinal study investigated the association of lipid profile variables with clinical and MRI markers of disease activity in subjects with highrisk clinically isolated syndrome [42]. High-density lipoprotein, low-density lipoprotein, and total cholesterol (TC) were not associated with clinical relapses, but higher low-density lipoprotein and TC levels were associated with an increased number of new T2 lesions over 2 years $(p=0.006$ and $p=$ 0.001 , respectively). Another cross-sectional study evaluated the frequency of cardiovascular risk factors in 489 people with MS to determine their association with T2 lesion volume [43]. After adjusting for age, sex, ethnicity, disease duration, and treatment status, there was increased T2 lesion volume in patients with RRMS with HTN who were cigarette smokers ( $p=$ 0.035). MS patients with HTN and heart disease who were overweight or obese also had increased T2 lesion volume ( $p=$ 0.009).

There is also growing evidence regarding the influence of vascular comorbidities on worsening disability in MS. One cohort study using the NARCOMS Registry assessed the time from MS diagnosis to ambulatory disability in people with and without vascular comorbidities [44]. Each vascular comorbidity reported at diagnosis (DM type II, HTN, CAD, PVD, or HPL) increased the risk of ambulatory disability by $50 \%$ (HR $1.51,95 \%$ CI 1.41-1.61). In addition, the median time from diagnosis to ambulatory disability was 6 years earlier in participants with vascular comorbidities than in those without. Another survey using NARCOMS data assessed whether vascular comorbidities affected the time between MS symptom onset and the development of mild, moderate, or severe visual disability [45]. In a multivariate Cox model adjusting for demographic and disease-related confounders, the risk of visual disability increased with the number of vascular comorbidities. For each comorbid vascular risk factor, there was a $45 \%$ increased risk for mild visual disability (HR 1.45, 95\% CI 1.39-1.51), 49\% increased risk for moderate 
Table 1 Prevalence estimates of vascular comorbidities in multiple sclerosis

\begin{tabular}{|c|c|c|c|c|}
\hline Comorbidity & $\begin{array}{l}\text { Number of } \\
\text { studies }\end{array}$ & $\begin{array}{l}\text { Years of } \\
\text { study }\end{array}$ & $\begin{array}{l}\text { Prevalence range } \\
(\%)\end{array}$ & Summary statistic \\
\hline DM type II & 39 & 1930-2009 & $6.75-8.57$ & - \\
\hline HPL & 13 & 1984-2010 & $3.0-47.8$ & $\begin{array}{l}10.9 \%(95 \% \text { CI } 5.6-16.1){ }^{\dagger} \\
\quad\left(I^{2}=94.9 \%\right)\end{array}$ \\
\hline HTN & 20 & 1997-2009 & $0-47.8$ & $\begin{array}{l}18.6(95 \% \text { CI } 13.9-23.2 \%) \\
\quad\left(I^{2}=89.9 \%\right)\end{array}$ \\
\hline CAD & 14 & 1979-2009 & $0.78-22.2$ & $\begin{array}{l}2.50 \%(95 \% \text { CI } 0-5.77 \%),^{\dagger} \\
\quad\left(I^{2}=97.6 \%\right)\end{array}$ \\
\hline CVD & 10 & 1977-2010 & $0.4-7.0,{ }^{\S} 1.2-1.4^{\mathrm{II}}$ & $\begin{array}{l}3.28 \%(95 \% \text { CI } 0-8.98 \%), \text {, } \\
\quad\left(I^{2}=97.4 \%\right)\end{array}$ \\
\hline PVD & 3 & $2000-07$ & $1-4 \%$ & $\begin{array}{l}2.40 \%(95 \% \text { CI } 0-5.14 \%),{ }^{\ddagger} \\
\quad\left(I^{2}=88.2 \%\right)\end{array}$ \\
\hline
\end{tabular}

Adapted from [41]

DM type II = diabetes mellitus type II; HPL = hyperlipidemia; $\mathrm{CI}=$ confidence interval; $\mathrm{HTN}=$ hypertension; $\mathrm{CAD}=$ coronary artery disease $\mathrm{CVD}=$ cerebrovascular disease $; \mathrm{PVD}=$ peripheral vascular disease

${ }^{\dagger}$ Based on 3 population-based studies

${ }^{\star}$ Based on 2 population-based studies

${ }^{\S}$ Ischemic or hemorrhagic stroke

${ }^{\text {II }}$ Ischemic stroke visual disability (HR 1.49, 95\% CI 14.0-1.59), and 37\% increased risk for severe visual disability (HR 1.37, $95 \%$ CI $1.22-1.53)$.

Other observational studies support an association between vascular comorbidities and increased risk of MSrelated disability. In a cohort study of 2083 people from a single, large MS center [9], HTN and DM type II were associated with poorer performance on walking speed and self-reported disability as measured by the Timed 25-Foot Walk [46] and Performance Scales score [47]. In an Israeli cohort study, 2396 people were followed to assess the impact of vascular comorbidities on the risk of progression to EDSS scores of 4.0, 6.0, and 8.0 [48]. People with HTN had a higher risk of reaching each EDSS milestone than people without vascular risk factors. A cohort study in southern Tasmania prospectively followed 178 people with MS from 2002 to 2005 [38]. After adjustment for confounders, TC, apolipoprotein B, and the apolipoprotein B:apolipoprotein A-I ratio were independently associated with a higher EDSS score.

\section{Impact of Vascular Comorbidities on Mortality in MS}

Three studies found that certain vascular comorbidities were associated with an increased mortality risk in MS. The first study, using provincial data from Manitoba, Canada, identified 5797 persons with MS using a validated administrate case definition [49]. These cases were paired with 28,807 controls. After stratifying by birth cohort and adjusting for sex, socioeconomic status, and region, multiple comorbidities were associated with an increased hazard of death in MS, including DM type II (HR $1.47,95 \%$ CI 1.25-1.73) and ischemic heart disease (HR 1.50, 95\% CI 1.28-1.75). The magnitude of the associations of mortality with DM type II and ischemic heart disease was lower in the MS population than the matched controls. The second study was a retrospective analysis of primary care data from a large administrative database in the UK [50]. In total, 1713 incident MS cases were identified and validated using electronic and original medical records. The adjusted HR for heart disease with respect to all-cause mortality was 2.2 (95\% CI 1.2-4.2). MS cases were not compared with controls. The third study utilized survey data from NARCOMS Registry participants who completed a Fall 2006 survey on comorbidities until death or date of last follow-up [51]. In total, 9496 subjects met the inclusion criteria. Using a linear regression model, vascular comorbidities were associated with increased mortality risk after adjusting for age at symptom onset, sex, education level, DMT use, smoking status, the Cognitive Performance Scale, and PDDS (HR 1.368, 95\% CI 1.128-1.659).

At least 2 cause-of-death studies suggested an increased mortality risk from vascular disease in MS populations versus the general public. A Danish population-based registry of patients with MS showed a 34\% increased risk of death from cardiac and vascular diseases versus the general population (standardized mortality ratio $1.34,95 \%$ CI $1.02-1.71$ ) [52]. The association was even stronger in a UK cohort study comparing patients with MS to sex-matched controls [27]. 
However, an older population-based survey from Wales performed in 1985 failed to find a difference between the proportion of cardiovascular disease-related deaths in people with MS and the general population [53]. It is important to note that these studies were subject to certain limitations. First, they did not compare mortality among individuals with and without cardiovascular disease. Second, cardiovascular disease in the studied populations could have increased mortality indirectly without being listed as the cause of death. Third, death certificates may have been inaccurate.

\section{Psychiatric Comorbidities}

Psychiatric comorbidities can have a major impact on quality of life but are often overlooked in clinical practice [54-59]. In a survey of 3884 patients with MS, $60 \%$ of people reported mental health problems, but fewer than half of these individuals received pharmacological or psychological treatment [60]. In another study of patients with MS over 45 years of age, $<16 \%$ with mental health disorders received mental health services [61]. One of the most concerning issues is the high rate of reported suicide among people with MS [62], especially if psychiatric comorbidities are underrecognized and under-treated in this population. However, findings from a recent large cohort study question whether suicide rates in people with MS are any different from population norms [63].

Most of the literature on psychiatric comorbidities in MS focuses on depression and bipolar disorder (BPD), so these are the 2 mood disorders discussed. There is also some literature on anxiety and stress management, which are discussed in the following section.

\section{Diagnosis of Mood Disorders}

The diagnosis of depression can be challenging because symptoms of depression align with some symptoms of MS (e.g., fatigue, altered sleep patterns, and poor concentration or memory). Various screening tests for depression have been studied in the MS population to help with recognition and early treatment. A recent systematic review identified 21 studies evaluating 12 instruments, including a 2-item screen, the Beck Depression Inventory, Center for Epidemiologic Studies Depression Scale, Chicago Multiscale Depression Inventory, Hospital Anxiety and Depression Scale (HADS), and Patient Health Questionnaire-9 [64]. Only 3 screening tests assessed sensitivity and specificity against the gold-standard Diagnostic and Statistical Manual of Mental Disorders diagnosis of major depressive disorder. For these tests, the sensitivity and specificity were as follows: HADS $(90 \%, 87 \%)$, Beck Depression Inventory $(71 \%, 79 \%)$, and the 2-item screen $(51 \%, 98 \%)$. Structural validity was assessed for some of the tests using confirmatory factor analysis. For these tests, structural validity was judged to be excellent for Chicago Multiscale Depression Inventory and acceptable for Center for Epidemiologic Studies Depression Scale and Patient Health Questionnaire-9. Currently there are no validated screening tools for BPD in MS.

\section{Prevalence of Mood Disorders and Impact on MS}

Reports on the prevalence of depression and BPD in the MS population have varied widely [65], likely owing to differences in the target population, types of measures used, and the time frame for evaluation. Nevertheless, prevalence rates are consistently high. A recent systematic review by Marrie et al. [65] identified 15 population-based studies reporting estimates of depression ranging from $4.98 \%$ to $58.9 \%$, with a summary estimate of $23.7 \%$ (95\% CI 17.4-30.0\%), but heterogeneity was high $\left(I^{2}=97.3\right)$. All 10 studies including a comparator population found a higher prevalence of depression in the MS population. Twelve studies were included that reported estimates of BPD ranging from $0 \%$ to $16.2 \%$. The only population-based study estimated the prevalence of BPD to be $5.83 \%$ [66]. All studies including a comparator population found the prevalence of BPD to be higher in the MS population.

Depression and BPD have a major impact on quality of life in MS [54-58], and depression affects multiple functional domains, including energy, cognition, perception of health, and sexual function [54-57, 67-69]. Moreover, patients with MS with depression may have worse long-term outcomes as a result of decreased adherence to DMTs [70].

\section{Anxiety and Stress}

Anxiety disorders are also common in MS and can impact disease activity and quality of life. The same systematic review by Marrie et al. [65] identified 8 population-based studies reporting the prevalence of anxiety (generalized or unspecified) to range between $1.2 \%$ and $44.6 \%$, with a summary estimate of $21.9 \%$ (95\% CI 8.76-35.0), but heterogeneity among the studies was high $\left(I^{2}=99.2\right)$.

Anxiety has been associated with clinical disease activity in MS. A post-hoc analysis of 121 people with MS enrolled in a randomized controlled trial (RCT) of a stress-management program had participants complete monthly self-reports on anxiety symptoms using the HADS anxiety subscale [71]. After controlling for baseline anxiety, treatment assignment, baseline EDSS score, baseline energy level, and demographics, confirmed exacerbations were associated with concurrent anxiety symptoms $(\beta=0.20 ; p<0.01)$. A prospective longitudinal study of 36 people with MS also evaluated the relationship between stressful life events, psychological distress, and disease activity as measured by gadoliniumenhancing (GdE) lesions on brain MRI [72]. Increased 
conflict and disruption in routine was associated with increased odds of developing new GdE lesions 8 weeks after baseline (OR 1.64; $p=0.001$ ) but not at baseline, 4 weeks, or 12 weeks. The study was limited in that it did not control for all important confounders, including treatment status of the participants, who were all selected from a placebo-controlled trial of IFN $\beta-1 b$.

Anxiety can also have a significant impact on quality of life. A systematic review of all studies related to anxiety and MS identified 8 cross-sectional studies and 2 prospective studies, all of which reported a statistically significant inverse association between anxiety and quality of life, although only abstracts were available for review for 4 studies [59].

\section{Suicide Risk and MS}

A 2012 systematic review was conducted to determine the potential association between MS and suicidal behavior [62]. Although a couple of studies were unable to find an increased risk of suicide attempts or suicide-related deaths in MS populations versus the population at large, 10 studies found rates of completed suicide 1.6- to 14-times higher than the general public. The idea that suicide rates are higher in people with MS has been called into question by a recent retrospective cohort study conducted in France [63]. In total, 27,603 prevalent cases of MS were previously assembled from a study on long-term mortality. Three percent of deaths were suicides. Even after including 36 suspected suicides in the MS population, there was no difference in mortality rate compared with population norms (standardized mortality ratio $1.01,95 \% \mathrm{CI}$ 0.80-1.26).

\section{Lifestyle Factors}

\section{Vitamin D}

\section{Vitamin D Metabolism and the Impact of Vitamin D on the Immune System}

Vitamin D3 is obtained from the diet or synthesized in the skin by ultraviolet $\mathrm{B}$ radiation, after which it is transported in the blood by the vitamin $\mathrm{D}$ binding protein. In the liver, it is converted to $25(\mathrm{OH}) \mathrm{D} 3$, which is the major circulating form of vitamin $\mathrm{D}$. It is then transported to the kidney where $25(\mathrm{OH}) \mathrm{D} 31-\alpha$-hydroxylase converts $25(\mathrm{OH}) \mathrm{D} 3$ to the active form of vitamin D, 1,25-dihydroxyvitamin D3 [1,25(OH)2D3] [73-75].

In addition to its role as a regulator of calcium and phosphate homeostasis, vitamin D affects the differentiation and function of certain cells in the immune system. Interest in the relationship between vitamin $\mathrm{D}$ and the immune system began in the 1980s with the discovery that specific high-affinity
$1,25(\mathrm{OH}) 2 \mathrm{D} 3$ receptors are located on the surface of immune cells [76-79]. In early experiments, T cells treated with $1,25(\mathrm{OH}) 2 \mathrm{D} 3$ showed decreased proliferation and secreted fewer proinflammatory cytokines (IFN- $\gamma$ and IL-2) than T cells without exposure to $1,25(\mathrm{OH}) 2 \mathrm{D} 3$ [80-82]. In addition, $1,25(\mathrm{OH}) 2 \mathrm{D} 3$ suppresses the activity of proinflammatory Th17 and Th1 cells that are implicated in MS disease activity [83-86]. 1,25(OH)2D3 also promotes regulatory $\mathrm{T}$ cells, which help protect against autoimmunity $[86,87]$.

\section{Impact of Vitamin D on MS Disease Activity and Worsening} of Disability

There is preliminary evidence supporting an inverse correlation between vitamin $\mathrm{D}$ levels and disease activity in MS from various cross-sectional studies. Two studies, one in Argentina and one in Finland, showed significantly lower serum $25(\mathrm{OH}) \mathrm{D}$ levels $(p<0.01$ and $p=0.03$, respectively) in patients with RRMS at times of relapse compared with remission, with a mean difference of $8.8 \mathrm{ng} / \mathrm{ml}$ and $15 \mathrm{ng} / \mathrm{ml}$, respectively [88, 89]. In a cross-sectional study of 267 people with MS from the Netherlands, examiners counted the number of relapses over a 2-year period before acquiring serum samples to determine the 1-year relapse rate. After controlling for age, sex, and disease duration, the relative risk (RR) of remaining relapse free in the previous 2 years increased by $51 \%$ for each $4 \mathrm{ng} / \mathrm{ml}$ increase of $25(\mathrm{OH}) \mathrm{D}(p=0.017)$, despite comparable disability scores [90].

Each of these studies had limitations. Although people in the Argentinian and Finnish studies were not treated with DMTs, there is no mention of controlling for DMT use in the Netherlands study. Moreover, only the Argentinian study evaluated differences in vitamin D levels due to dietary supplements and place of residence, and only the Finnish study controlled for differences in vitamin D levels due to seasonal variation.

Additional observational studies have shown an inverse correlation between vitamin D levels and disability [90, 91]. In the previously described study from the Netherlands, EDSS scores were assessed at the time of serum sampling. 25(OH)D levels were a significant predictor of EDSS both before and after adjusting for confounders, although the effect size was low (adjusted OR $-0.014,95 \% \mathrm{CI}-0.022$ to -0.006 ). In addition, a population-based case-control study in Tasmania, Australia, compared 25(OH)D levels in patients with MS and healthy controls. Among patients with MS, those with higher disability (EDSS $>3$ ) were more likely to have vitamin D insufficiency $[25(\mathrm{OH}) \mathrm{D} \leq 16 \mathrm{ng} / \mathrm{ml}]$ than healthy controls (OR 3.07, 95\% CI 1.37-6.90), but those with less disability were less likely to be vitamin D insufficient (OR $0.87,95 \% \mathrm{CI}$ 0.41-1.86)) [91]. In both of these studies, the association between vitamin $\mathrm{D}$ levels and disability might have been a reflection of lower sun exposure in people with more severe MS 
rather than a direct relationship between vitamin $\mathrm{D}$ and disability.

More robust evidence comes from longitudinal cohort studies. A 5-year cohort study showed that higher vitamin D levels were associated with decreased MRI disease activity and decreased disability for people with clinically isolated syndrome or RRMS [92]. In multivariate analyses adjusting for age, ethnicity, race, tobacco smoking, and MS treatment, each $10 \mathrm{ng} / \mathrm{ml}$ higher 25(OH)D level was associated with a $15 \%$ lower risk of a new T2 lesion (IRR $0.85,95 \%$ CI 0.76 0.95 ) and a $32 \%$ lower risk of a new GdE lesion (IRR 0.68, 95\% CI 0.53-0.87). In addition, each $10 \mathrm{ng} / \mathrm{ml}$ higher $25(\mathrm{OH}) \mathrm{D}$ level was associated with a 0.05 -point lower subsequent EDSS score (95\% CI -0.091 to -0.003$)$.

Moreover, 2 prospective cohort studies including participants from large RCTs found an association between 25(OH)D levels and markers of disease activity and worsening disability $[93,94]$. One study involving participants in the BEYOND trial found a significant inverse correlation between average 25(OH)D levels in 1482 people and the cumulative number of new active lesions, defined as the sum of new $\mathrm{T} 2$ lesions and new GdE lesions between baseline and the most recent brain MRI [93]. A $20 \mathrm{ng} / \mathrm{mL}$ increase in serum $25(\mathrm{OH}) \mathrm{D}$ levels was associated with a $31 \%$ lower rate of new T2 lesions (RR $0.69,95 \%$ CI $0.55-0.86$ ). The lowest rate of new T2 lesions was observed among people with 25(OH)D levels $>40 \mathrm{ng} / \mathrm{mL}$ (RR 0.53, 95\% CI 0.37-0.78). Another study including participants in the BENEFIT trial found that a $20 \mathrm{ng} / \mathrm{ml}$ increase in $25(\mathrm{OH}) \mathrm{D}$ levels was associated with a reduction of 0.16 points in the average EDSS score $(p=0.11)$, supporting an association between low $25(\mathrm{OH}) \mathrm{D}$ levels and worsening of disability [94].

Multiple phase I and II RCTs have now been conducted to assess the safety and utility of vitamin D supplementation [95-100]. None of these studies was powered for clinical outcomes measures, and only 1 of these studies [97] was powered for an MRI measure of disease activity. This 1-year, randomized, double-blind, placebo-controlled trial evaluated 20,000 international units of vitamin D3 as an add-on therapy to IFN $\beta-1 b$. Total T2 lesion volume was the primary endpoint. Median change in T2 lesion volume was $287 \mathrm{~mm}^{3}$ in the placebo group versus $83 \mathrm{~mm}^{3}$ in the treatment group, but the difference did not meet statistical significance $(p=0.105)$. The total number of GdE lesions, a secondary endpoint, decreased in both groups $(p=0.002)$, but this change was significantly higher in the vitamin D group ( $p=0.004)$, with a change in the median number of lesions from 0.6 to 0.1 in the treatment arm. Several ongoing RCTs are investigating the utility of vitamin $\mathrm{D}$ as adjunctive therapy to DMTs and may help provide a more definitive answer regarding the impact of vitamin $\mathrm{D}$ on disease activity and worsening of disability in MS [101-103]. Key features of these preliminary and ongoing RCTs are summarized in Table 2.

\section{Tobacco Smoking}

Impact of Tobacco Smoking on the Immune System

At least 98 chemicals in tobacco smoke have an established health risk. In addition to carcinogenic effects, many of these chemicals affect the immune system [104]. These effects may be mediated, at least in part, by T helper 17 cells [105]. The aryl hydrocarbon receptor has been proposed as a possible link between toxins in tobacco smoke and $\mathrm{T}$ helper 17-cellmediated autoimmunity [106-108].

\section{Impact of Tobacco Smoking on MS Disease Activity and Worsening of Disability}

Although no studies evaluating the association between smoking and MS disease activity were identified, multiple studies demonstrate increased risk of disability and worse long-term outcomes in people with MS who smoke tobacco [109-115]. A 2011 meta-analysis of 4 cohort studies investigating the impact of smoking on conversion from RRMS to secondary progressive MS (SPMS) suggested an increased risk in smokers but fell short of statistical significance (RR 1.88, 95\% CI 0.98-3.61) [116]. A separate cross-sectional study of 728 smokers from the Swedish National MS Registry assessed the time to conversion from RRMS to SPMS. Their model estimated that each additional year of smoking after diagnosis accelerated the time to conversion to SPMS by $4.7 \%$. Furthermore, those who continued to smoke converted to SPMS earlier than those who stopped smoking $(p=0.006)$. The median age at conversion to SPMS was 48 years in those who continued to smoke versus 56 years in those who quit [117]. A recent prospective cohort study of 646 people in Queensland, Australia, also showed an increased risk of progression from RRMS to SPMS in people with a history of smoking [118].

Other studies have investigated the impact of tobacco smoking on reaching key disability milestones. In a UK cohort study of 895 people with MS, the risk of reaching an EDSS score of 4.0 and 6.0 was higher in those who had a history of smoking than in those who never smoked [RR 1.34 (95\% CI 1.12-1.60) and RR 1.25 (95\% CI 1.02-1.51), respectively] [114]. Exsmokers had a significantly lower risk of reaching an EDSS score of 4.0 (HR $0.65,95 \%$ CI $0.50-0.83$ ) and an EDSS score of 6.0 (HR $0.69,95 \%$ CI $0.53-0.90$ ) than current smokers. In addition, a cross-sectional study of 1372 people in Belgium found an association between smoking and increased risk for reaching an EDSS score of 6.0 compared with ex-smokers and never smokers [109]. 
Table 2 Summary of vitamin D randomized controlled trials

\begin{tabular}{|c|c|c|c|c|c|}
\hline Study & Duration & Population & $\begin{array}{l}\text { Intervention/ } \\
\text { comparator }\end{array}$ & Results & Power \\
\hline $\begin{array}{l}\text { Burton et al. } \\
\text { [95] }\end{array}$ & 52 weeks & $\begin{array}{l}\text { RRMS } \\
\text { and } \\
\text { SPMS }\end{array}$ & $\begin{array}{l}\text { High-dose D3 } \\
\text { titration up to } \\
40,000 \text { IU per day } \\
\text { followed by taper } \\
(n=25) v s \\
4000 \text { IU D3 per } \\
\text { day or less } \\
(n=24)\end{array}$ & $\begin{array}{l}\text { No significant } \\
\text { difference } \\
\text { in ARR or } \\
\text { EDSS }\end{array}$ & $\begin{array}{l}\text { Not powered to } \\
\text { assess clinical } \\
\text { outcomes }\end{array}$ \\
\hline $\begin{array}{l}\text { Kampman et al. } \\
\text { [96] }\end{array}$ & 96 weeks & MS & $\begin{array}{l}20,000 \text { IU D3 per } \\
\text { week }(n=35) v s \\
\text { placebo }(n=33)\end{array}$ & $\begin{array}{l}\text { No significant } \\
\text { difference } \\
\text { in ARR, } \\
\text { EDSS, or } \\
\text { MSFC }\end{array}$ & $\begin{array}{l}\text { Not powered to } \\
\text { assess clinical } \\
\text { outcomes }\end{array}$ \\
\hline Stein et al. [99] & 6 months & RRMS & $\begin{array}{l}1000 \mathrm{IU} \\
\mathrm{D} 2+\text { high-dose } \\
\mathrm{D} 2 \text { daily }(n=11) \\
v s 1000 \mathrm{IU} \\
\mathrm{D} 2+\text { placebo } \\
\text { daily }(n=12)\end{array}$ & $\begin{array}{l}\text { No significant } \\
\text { difference } \\
\text { in new GdE } \\
\text { lesions } \\
(p=0.70) \\
\text { or T2 BOD } \\
(p=0.60)\end{array}$ & $\begin{array}{l}\text { No power } \\
\text { calculation } \\
\text { attempted }\end{array}$ \\
\hline $\begin{array}{l}\text { Soilu-Hanninen } \\
\text { et al. [97] }\end{array}$ & 1 year & RRMS & $\begin{array}{l}\text { IFN } \beta- \\
1 \mathrm{~b}+20,000 \mathrm{IU} \\
\mathrm{D} 3 \text { every week } \\
(n=34) v s \\
\text { IFN } \beta- \\
1 \mathrm{~b}+\text { placebo } \\
(n=32)\end{array}$ & $\begin{array}{l}\text { No significant } \\
\text { difference } \\
\text { in T2 BOD } \\
(p=0.105)\end{array}$ & $\begin{array}{l}80 \% \text { power to } \\
\text { detect a } \\
1000 \mathrm{~mm}^{3} \\
\text { difference in } \mathrm{T} 2 \\
\text { BOD }\end{array}$ \\
\hline $\begin{array}{l}\text { Bhargava et al. } \\
\text { [103] } \\
\text { (ongoing) }\end{array}$ & 96 weeks & RRMS & $\begin{array}{l}\text { GA + } 5000 \text { IU D3 } \\
\text { daily } v s \\
\text { GA + 600 IU D3 } \\
\text { daily }\end{array}$ & $\begin{array}{l}\text { Primary } \\
\text { endpoint: } \\
\text { proportion } \\
\text { of subjects } \\
\text { with } \\
\text { relapses }\end{array}$ & $\begin{array}{l}80 \% \text { power to } \\
\text { detect a } 57 \% \\
\text { decrease in the } \\
\text { proportion of } \\
\text { subjects with } \\
\text { relapses }\end{array}$ \\
\hline $\begin{array}{l}\text { Dorr et al. [102] } \\
\text { (ongoing) }\end{array}$ & 18 months & $\begin{array}{l}\text { CIS or } \\
\text { RRMS }\end{array}$ & $\begin{array}{l}\text { IFN } \beta- \\
1 \mathrm{~b}+10,200 \text { IU } \\
\text { D3 daily } v s \\
\text { IFN } \beta- \\
1 \mathrm{~b}+200 \text { IU D3 } \\
\text { daily }\end{array}$ & $\begin{array}{l}\text { Primary } \\
\text { endpoint: } \\
\text { cumulative } \\
\text { number of } \\
\text { new T2 } \\
\text { lesions }\end{array}$ & $\begin{array}{l}83 \% \text { power to } \\
\text { detect a mean } \\
\text { reduction of } 1.5 \\
\text { new T2 lesions }\end{array}$ \\
\hline $\begin{array}{l}\text { Smolders et al. } \\
\text { [101] } \\
\text { (ongoing) }\end{array}$ & 96 weeks & RRMS & $\begin{array}{l}\text { IFN } \beta-1 \mathrm{a}+7000 \text { or } \\
14,000 \text { IU D3 } \\
\text { daily vs IFN } \beta- \\
1 \mathrm{a}+\text { placebo }\end{array}$ & $\begin{array}{l}\text { Primary } \\
\text { endpoint: } \\
\text { composite } \\
\text { MRI and } \\
\text { clinical } \\
\text { outcome }\end{array}$ & $\begin{array}{l}80 \% \text { power to } \\
\text { detect an increase } \\
\text { from } 53 \% \\
\text { (placebo group) } \\
\text { to } 69 \% \text { (vitamin } \\
\text { D3 group) in the } \\
\text { proportion of } \\
\text { relapse-free peo- } \\
\text { ple }\end{array}$ \\
\hline
\end{tabular}

RRMS = relapsing-remitting multiple sclerosis; SPMS = secondary progressive multiple sclerosis; ARR = annualized relapse rate; EDSS = Kurtzke Expanded Disability Status Scale; MS = multiple sclerosis; MSFC = MS Functional Composite; GdE = gadolinium-enhancing; $\mathrm{BOD}=$ burden of disease; IFN = interferon; GA = glatiramer acetate; CIS = clinically isolated syndrome

\section{Impact of Tobacco Smoking on Mortality in MS}

Tobacco smoking is associated with increased mortality in people with MS [27, 50, 52, 119-122]. In one UK population-based cohort study, 1270 people with MS had a 3.5-fold increased all-cause mortality rate (95\% CI 2.63-4.69) versus age- and sex-matched controls. The mortality rate further increased in current smokers compared with ex-smokers 
(HR 6.7, 95\% CI 4.16-10.9) [27]. This relationship was also observed in a retrospective analysis of primary care data for patients with MS from a UK national registry, where current smokers had a mortality rate twice as high as nonsmokers (95\% CI 1.2-3.4) [50]. A study from the US showed similar findings. Data from the US Department of Veterans Affairs MS National Data Repository was combined with the Veterans Affairs 1999 Large Veteran Health Survey to assess current lifestyle behaviors in veterans with MS. After adjusting for demographic factors, physical functioning, mental health, and comorbid medical conditions, baseline smoking was associated with an increased risk of mortality with a HR of 1.38 (95\% CI 1.18-1.60) [123].

\section{Summary Points on Comorbidities and Lifestyle Factors in MS}

Overall, there is insufficient evidence to support a strong association between weight status and disease activity or worsening disability in MS. Multiple cohort studies show an association between vascular comorbidities and higher levels of disability in MS, and 2 population-based studies show an increased hazard of death in people with MS who have certain vascular comorbidities. Psychiatric comorbidities are common in MS, have a major impact on quality of life, and are often undertreated in the MS population. There is preliminary evidence from several longitudinal cohort studies supporting an inverse correlation between vitamin D levels and both MRI disease activity and worsening disability in MS. Multiple cross-sectional studies and 2 cohort studies found an association between tobacco smoking and worsening of MS-related disability, with worse outcomes for continued smokers than ex-smokers.

\section{Health and Wellness Practices in MS}

In addition to conventional medicine, there is growing public and scientific interest in incorporating lifestyle strategies to optimize MS care as part of an integrative model of medicine. Many of these interventions are rooted in a global approach to health and wellness that focuses on physical and emotional well-being, including diet, dietary supplements, physical activity, stress management, and tobacco cessation. Recommended wellness interventions are summarized in Table 3.

\section{Vitamin D Supplementation}

There is preliminary evidence from several longitudinal cohort studies showing an inverse correlation between vitamin D levels and MRI evidence of disease activity or worsening disability in MS [92-94]. Multiple RCTs are still ongoing and may provide definitive evidence for the effect of vitamin D on disease-related outcomes in MS [101-103]. Nevertheless, guidelines in the general population support vitamin D supplementation to a minimum level [124-126], which may have added benefits for people with MS.

\section{Optimal Vitamin D Levels}

Multiple studies investigating vitamin D supplementation in the general population [127-130], including an Institute of Medicine systematic review [131], favor serum 25(OH)D concentrations between 20 and $50 \mathrm{ng} / \mathrm{ml}$. The Endocrine Society, International Osteoporosis Foundation, and American Geriatric Society suggest that a minimum level of $30 \mathrm{ng} / \mathrm{ml}$ is necessary in older adults to minimize the risk of falls and fracture [124-126]. The Institute of Medicine systematic review voiced concern for serum 25(OH)D3 concentrations above $50 \mathrm{ng} / \mathrm{ml}$. These concerns were based on an increased risk of bone fractures in people treated with highdose vitamin D [130] and a potential increased risk of certain cancers (pancreatic and prostate) with 25(OH)D3 levels above 30 to $48 \mathrm{ng} / \mathrm{ml}$. The $25(\mathrm{OH}) \mathrm{D}$ level should be well below the critical threshold of $200 \mathrm{ng} / \mathrm{ml}$ that may lead to hypercalcemia [132].

\section{Recommendations for Vitamin D Supplementation}

In general, all people should be supplemented to a $25(\mathrm{OH}) \mathrm{D}$ level of at least $20 \mathrm{ng} / \mathrm{ml}$, and a level of $30 \mathrm{ng} / \mathrm{ml}$ is recommended by most guidelines. The optimal approaches for supplementation in the general population and in those with MS have not been established. The amount of vitamin D that is needed varies between individual people and depends on where one lives and the time of year. However, it is generally accepted that vitamin D3 is preferable to vitamin D2 because vitamin D3 is more active biologically, raises blood levels more effectively, and is more stable on the shelf [133].

While there are no specific guidelines on optimal vitamin D supplementation, a general strategy that may be effective in many parts of the US is vitamin D3 1000 IU for levels between 20 and $30 \mathrm{ng} / \mathrm{ml}$ and vitamin D3 2000 IU daily for levels $<20 \mathrm{ng} / \mathrm{ml}$ (vitamin D deficient). In some regions, such as the Pacific Northwest, higher doses may be necessary if one is vitamin D deficient: after initial treatment with 50,000 IU for 2 to 3 months, maintenance dosing with 2000 to 5000 IU daily may be needed. Importantly, these strategies for diagnosing and treating vitamin D deficiency are "best-guess" approaches based on current evidence [127-130]. Dosing will differ across ethnic groups and is affected by other factors, including obesity, the baseline $25(\mathrm{OH}) \mathrm{D}$ level, and the dose and type of vitamin D used for supplementation [134]. The optimal time to recheck a $25(\mathrm{OH}) \mathrm{D}$ level has not been clearly defined, but one RCT comparing 1000 IU with 4000 IU of 
Table 3 Principle recommendations for wellness interventions

\begin{tabular}{ll}
\hline Vitamin D supplementation & - Maintain a minimum 25(OH)D level of $30 \mathrm{ng} / \mathrm{ml}$ \\
- Vitamin D3 supplementation is preferred over vitamin D2 & - Although there is no established treatment approach, supplementation with \\
& $1000 \mathrm{IU}$ vitamin D3 for levels between 20 and $30 \mathrm{ng} / \mathrm{ml}$ and $2000 \mathrm{IU}$ of \\
& vitamin D3 for levels $<20 \mathrm{ng} / \mathrm{ml}$ is one general treatment approach
\end{tabular}

25(OH)D = 25-hydroxyvitamin D; NRT = nicotine-replacement therapy; NCHPAD = National Center on Health, Physical Activity and Disability; USDA = United States Department of Agriculture; BDI = Beck Depression Inventory; CES-D = Center for Epidemiologic Studies Depression Scale; CMDI = Chicago Multiscale Depression Inventory; HADS $=$ Hospital Anxiety and Depression Scale; PHQ-9 = Patient Health Questionnaire-9; BPD = bipolar disorder daily vitamin D3 supplementation found that levels peaked at 3 months, regardless of the dose [135].

Preliminary studies suggest high-dose vitamin D supplementation is well tolerated by MS people. Phase I and II trials of high-dose vitamin D3 have shown that patients with MS can tolerate doses as high as 20,000 IU daily for 12 weeks [136] and escalating doses of vitamin D3 up to 40,000 IU daily over 28 weeks [95] with minimal, if any, side effects. However, these findings are only based on a few studies for short intervals, and more definitive evidence is needed to support the safety of long-term, high-dose vitamin D supplementation. Several clinical trials are ongoing at this time and will provide more evidence regarding the safety and tolerability of vitamin D as adjunct therapy [101-103].

\section{Tobacco Smoking Cessation}

Optimal strategies in tobacco-smoking cessation include both behavioral and pharmacologic therapies [137]. Behavioral support interventions include written materials containing advice on quitting, multisession group therapy programs, and individual counseling. With respect to medications, nicotine replacement therapy, varenicline, bupropion, cytisine, and nortriptyline all increase the long-term success of quit attempts [138]. Combination therapy including varenicline and nicotine replacement therapy may be more effective than either treatment strategy alone [139].

\section{Recommendations for Tobacco-Smoking Cessation}

Given the association of tobacco smoking with an increased risk of worsening disability and mortality in MS, it is recommended that all people with MS do not smoke tobacco products [27, 52, 109-115, 117-123]. A combination of pharmacologic and behavioral interventions is the most effective in supporting people who wish to quit smoking.

\section{Diet and Nutrition}

Numerous dietary strategies have been popularized over the years with the intent of improving disease activity, disability, and quality of life in people with MS. The strategies that have received the most attention in the MS literature are summarized in Table 4. While there are few studies in support of a particular diet specifically for MS-related benefits, there are ongoing RCTs investigating the impact of a Mediterranean- 
Table 4 Summary of proposed dietary regimes in multiple sclerosis (MS)

\begin{tabular}{|c|c|c|c|}
\hline Diet & Specific dietary guidelines & Precautions & $\begin{array}{l}\text { Reference } \\
\text { to protocol }\end{array}$ \\
\hline $\begin{array}{l}\text { Mediterranean } \\
\text { diet }\end{array}$ & $\begin{array}{l}\text { - High proportion of fruits, vegetables, whole } \\
\text { grains, beans, nuts, and seeds } \\
\text { - Includes olive oil as a source of monounsaturated } \\
\text { fat } \\
\text { - Allows low-to-moderate consumption of red } \\
\text { wine }\end{array}$ & & $\begin{array}{r}\text { Stamler } \\
{[140]}\end{array}$ \\
\hline $\begin{array}{l}\text { Low-sodium } \\
\text { diet }\end{array}$ & $\begin{array}{l}\text { - No MS-specific recommendations exist regard- } \\
\text { ing the optimal limit to dietary sodium intake } \\
\text { - } 2015 \text { United States Dietary Guidelines } \\
\text { recommend that adults consume } \leq 2300 \mathrm{mg} \\
\text { sodium per day [141] }\end{array}$ & & - \\
\hline Paleolithic diet & $\begin{array}{l}\text { - Emphasizes consumption of vegetables, roots, } \\
\text { game meats rather than domesticated meats, and } \\
\text { organ meats } \\
\text { - Excludes dairy products, foods with a high } \\
\text { glycemic content, highly processed foods } \\
\text { - A version of the Paleolithic diet, the Wahls } \\
\text { protocol, has been popularized by Dr. Terry } \\
\text { Wahls from her experience with the impact of } \\
\text { dietary changes on her own disease course in } \\
\text { MS }\end{array}$ & $\begin{array}{l}\text { May be at risk for } \\
\text { vitamin D and E } \\
\text { deficiency [142] }\end{array}$ & $\begin{array}{l}\text { Wahls and } \\
\text { Adamso- } \\
\mathrm{n}[143]\end{array}$ \\
\hline Swank diet & $\begin{array}{l}\text { - Limit consumption of saturated fats to } 15 \mathrm{~g} / \text { day } \\
\text { - Keep consumption of unsaturated } \\
\text { fats }<20-50 \mathrm{~g} / \text { day } \\
\text { - Fat from dairy products and red meat is strictly } \\
\text { limited } \\
\text { - White fish, shellfish, whole grains, and cod liver } \\
\text { oil are encouraged }\end{array}$ & $\begin{array}{l}\text { May be at risk for } \\
\text { folate and vitamin } \\
\text { A, C, and E } \\
\text { deficiency [142] }\end{array}$ & $\begin{array}{l}\text { Swank } \\
{[144]}\end{array}$ \\
\hline $\begin{array}{l}\text { Gluten-free } \\
\text { diet }\end{array}$ & $\begin{array}{l}\text { - Completely devoid of gluten-containing } \\
\text { products, primarily found in wheat, barley, and } \\
\text { rye }\end{array}$ & - & - \\
\hline $\begin{array}{l}\text { Intermittent } \\
\text { fasting }\end{array}$ & $\begin{array}{l}\text { - Various regimens have been proposed, including } \\
\text { alternate day fasting, when food is consumed } \\
\text { every other day }\end{array}$ & & $\begin{array}{l}\text { Varady } \\
\text { et al. } \\
{[145]}\end{array}$ \\
\hline
\end{tabular}

style diet (NCT02986893), calorie restriction (NCT02411838, NCT02846558), low-sodium diet (NCT02282878), and Paleolithic diet (NCT02914964) with respect to clinical outcomes in MS.

\section{Clinical Trials}

Apart from studies on dietary supplements, there is only 1 published RCT investigating the clinical impact of a specific dietary intervention in MS. Yadav et al. [146] conducted a 1-year-long trial in which 61 participants were randomized to either a low-fat, plant-based diet, or control [146]. All subjects had RRMS, a documented clinical relapse or active disease by MRI in the previous 2 years, and a baseline diet with $>30 \%$ of caloric intake from fat. The study diet was based on starchy plant foods with approximately $10 \%$ of calories from fat,
$14 \%$ from protein, and $76 \%$ from carbohydrates. Adherence to the study diet was good with the intervention group showing a significant difference in the proportion of total caloric intake from fat compared with the control group ( $15 \%$ vs $40 \%$, respectively). The 2 groups showed no differences in brain MRI outcomes, number of MS relapses, or disability at 12 months. The diet group showed significant improvements at 6 months in measures of fatigue, with the mean Fatigue Severity Scale improving by 0.06 points/month $(p=0.001)$ and Modified Fatigue Impact Scale improving by 0.23 points/month $(p=0.001)$. These changes were greater than the control group after controlling for baseline differences $\left(t=-3.88, p_{\text {adj }}=0.001 ; t=-3.85, p_{\text {adj }}=0.001\right.$, respectively). There was also an average reduction in BMI of $0.18 \mathrm{~kg} / \mathrm{m}^{2}$ per month in the diet group. This rate of weight loss was significant after correcting for 
baseline weight $\left(t=-3.94, p_{\text {adj }}<0.001\right)$ and was faster than the control group $\left(t=-3.68, p_{\text {adj }}<0.001\right)$.

\section{Observational Studies}

A handful of observational studies have also been conducted to investigate the impact of different diets. One of the bestdesigned studies was a prospective cohort study evaluating the impact of a high-sodium diet, estimated by urine sodium levels, on clinical relapses and MRI disease activity in people with MS. There was a statistically significant positive correlation between estimated sodium intake and clinical and MRI activity after adjusting for age, sex, disease duration, treatment, vitamin D levels, BMI, and smoking status [147]. Compared with the baseline intake group (sodium $<2 \mathrm{~g} /$ day), the average intake (sodium 2-4.8 g/day) and aboveaverage intake groups (sodium $\geq 4.8 \mathrm{~g} /$ day) had relapse rates that were 2.75 -fold (95\% CI 1.3-5.8) and 3.95-fold (95\% CI 1.4-11.2) higher than the baseline group. No significant differences were found in terms of EDSS either at baseline or at the end of follow-up. Individuals with a sodium intake above the national average had a 3.4-fold increased chance of developing a new lesion on brain MRI (95\% CI 1.37-8.55) and had, on average, 8 more T2-weighted lesions. The findings suggest a correlation between sodium levels and clinical and MRI evidence of disease activity, but additional studies are warranted for further investigation.

Another prospective cohort study evaluated the impact of prolonged intermittent fasting on the course of MS in a cohort of people in Iran [148]. The cohort consisted of 40 adult patients with MS who fasted during Ramadan and 40 patients with MS who did not fast. Only people with mild disability $(\operatorname{EDSS} \leq 3)$ were included in the study. All people were followed for 6 months after Ramadan to assess their EDSS score changes and to record the number of clinical relapses. At the end of the study, no significant changes in EDSS or the frequency of clinical relapses were detected between the 2 groups. Fasting had no short-term adverse effects. Disease duration, relapse rate, and the use of DMTs were similar between the 2 groups, but the potential impact of other confounders was not assessed.

Other studies were not as robust. A very small, openlabel, single-arm study evaluated a multimodal intervention strategy, including a modified Paleolithic diet, additional dietary supplements, stretching and strengthening exercises with electrical stimulation, meditation, and massage for people with SPMS [149]. Only 8 of 10 subjects completed the study and only 6 were fully adherent to the entire program. For those who completed the study, there was an improvement in fatigue, but no clear correlation with the dietary regimen was made.

\section{US Dietary Guidelines}

US dietary guidelines are developed every 5 years from an advisory committee composed of experts in the field of nutrition, health, and medicine. They are general recommendations for promoting overall health and preventing chronic disease, and they incorporate scientific evidence from systematic reviews that assess eating patterns and their association with disease [150]. These guidelines emphasize a low-salt, lowfat diet with a high proportion of fruits and vegetables, a variety of proteins, and high-fiber foods. This diet is considered healthy for the general US population, and may have added benefits for people with MS. Many of these same interventions are currently being studied in the ongoing dietary RCTs for MS.

\section{Recommendations for Diet and Nutrition}

While there is no convincing evidence in support of a particular diet in MS, a plant-based, anti-inflammatory, nutritional regimen appears to be the most strongly indicated for optimal health. The 2015 to 2020 Dietary Guidelines from the US Department of Agriculture include general dietary approaches with the goal of optimizing health and minimizing chronic diseases [150]. Such recommendations include a variety of vegetables, whole fruits, grains, fat-free or low-fat dairy products, a variety of proteins, high-fiber foods, and oils. The guidelines limit added sugars, processed foods, salt intake to $<2300 \mathrm{mg} /$ day, total fat in the diet to $20 \%$ to $35 \%$ of calories, saturated fat intake $<10 \%$ of calories, and trans fats.

\section{Weight Management}

To date, the authors are unaware of any clinical trials designed to assess the impact of weight-management strategies on disease-related outcomes in MS.

\section{Exercise}

An abundance of trials have investigated the effect of structured exercise programs on multiple functional and symptomatic outcomes in MS, including walking, fatigue, cognition, and spasticity. Significant variability exists between these trials with respect to the interventions used, duration and intensity of treatment, and populations studied. Most of these investigations found a beneficial impact of exercise on MS during treatment; however, it is not clear if these effects continue past the treatment period [151].

\section{Exercise and Safety}

Historically, there has been uncertainty regarding the potential adverse effects associated with exercise training in MS and 
whether exercise can trigger a relapse or worsen disease. To address this question, 1 systematic review attempted to identify all RCTs with an exercise intervention program and a "notreatment" comparator [152]. Twenty-six studies were included. Overall, the proportion of adverse effects and drop-out rates was similar between the control and exercise groups, and there were even fewer relapses in the intervention arm than in the control arm. The myth that exercise worsens MS has largely been debunked.

\section{Exercise and MS Performance Measures}

A systematic review estimated the effect of exercise on walking performance in MS by examining RCTs of structured exercise programs [153]. Study quality was reasonably high. In pooled analyses, structured exercise was associated with a significant improvement in measures of endurance, but there were inconsistent results for different measures of walking speed. There was no significant improvement in the Timed Up and Go test [154], the only measure of mobility in this study.

Another systematic review investigated the benefits of exercise in improving balance and reducing falls. RCTs and crossover trials were identified that compared strength training; endurance training; gait, balance, and functional training; and general exercise programs to usual care in adult people with MS [155]. In a pooled analysis, there was no significant difference in fall risk or balance between groups. However, the interpretation of these findings is complicated by significant heterogeneity between studies.

\section{Exercise and MS-Related Symptoms}

A Cochrane review evaluated the effectiveness and safety of exercise versus no exercise or an alternative intervention for fatigue in people with MS [156]. Fatigue was measured by self-reported questionnaires. Thirty-six trials were included in the meta-analyses. There was a significant effect on fatigue in favor of exercise therapy, but there was significant heterogeneity among studies. When considering the type of exercise, all interventions had a significant effect on fatigue. This included endurance training, mixed training with an endurance component, and "other" training, such as yoga and tai chi.

A review of exercise with respect to cognitive outcomes in MS found conflicting results and involved studies of relatively poor methodological quality [157]. Studies with higherquality ratings according to American Academy of Neurology guidelines (class I or II studies) tended to report nonsignificant effects, whereas studies with lower-quality ratings (class III or IV studies) tended to report beneficial effects. Nevertheless, a recent, single-blinded, randomized pilot trial of aerobic exercise training was conducted, enrolling 8 ambulatory women with MS. The study found small-to-moderate improvements on the California Verbal Learning Test-II $(\sim 4$ points, $d=0.34$ ) in the intervention group after 12 weeks of supervised, progressive treadmill walking [158].

A recent Cochrane review evaluated nonpharmacologic interventions for spasticity in MS [159]. Nine RCTs were included. None of the studies had low risk of bias as assessed by the Cochrane risk of bias tool. There was evidence to support physical activity programs used in isolation or in combination with other interventions (pharmacologic or nonpharmacologic) and repetitive magnetic stimulation with or without exercise therapy as interventions to improve spasticity. However, the strength of evidence was limited by the methodological quality of these studies.

\section{Yoga}

To investigate whether yoga improves quality of life in MS, a systematic review searched for all RCTs comparing the shortterm effects of yoga with usual care for a variety of outcomes [160]. Seven RCTs were included. There was a small but statistically significant impact on fatigue [standardized mean difference (SMD) 20.52, 95\% CI 21.02-20.02; $I^{2}=60 \%$ ] and mood (SMD 20.55, 95\% CI 20.96-20.13; $I^{2}=0 \%$ ) but not HRQoL, muscle function, or cognitive function. The effects on fatigue and mood were not robust against bias.

\section{Recommendations for Exercise}

Routine exercise is important in MS and should be encouraged. The US National Center on Health, Physical Activity and Disability Guidelines for people with MS recommend 20to 60 -min sessions of moderate-intensity aerobic training at least 3 to 4 days per week and 10- to 15-min sessions of strength training 2 to 3 days per week [161]. They also include daily stretching exercises for at least 10 to $15 \mathrm{~min}$. These guidelines caution people to monitor heart rate and blood pressure closely, if they have dysautonomia, and maintain a cool environment to avoid heat sensitivity, as this can exacerbate symptoms of MS.

\section{Treatment of Mood Disorders and Anxiety}

A recent systematic review searched for all controlled clinical trials reporting on the effect of pharmacological or psychological interventions for depression or anxiety in a sample of persons with MS [162]. They calculated SMDs and pooled results using random effects meta-analysis. Depression severity improved with desipramine, paroxetine, and sertraline use in 3 RCTs (SMD 0.45, 95\% CI 1.07-0.20) [163-165]. Heterogeneity among the studies was low $\left(I^{2} 10 \%, q=0.33\right)$. Moreover, in numerous open-label trials, duloxetine [166], fluoxetine [167], sertraline [168], and imipramine [169] were 
all found to be effective therapies. There is no indication that any particular medication is significantly more effective.

The same systematic review investigated nonpharmacologic interventions for depression and anxiety [162]. The severity of depression scores improved in 9 RCTs investigating psychological interventions for depression treatment (SMD 0.45, 95\% CI 0.74-0.16). Moderate heterogeneity existed between the study estimates $\left(I^{2}=53 \%, q=0.03\right)$, but after removing 1 outlier with an estimate 5 times larger than the rest, heterogeneity based on the $I^{2}$ was $0 \%(q=0.89)$. Most of the interventions focused on a form of cognitive behavioral therapy; however, 1 trial investigated motivational interviewing and goal-setting for physical activity. Anxiety severity did not significantly improve in any of the 3 psychological trials of depression treatment, all of which employed cognitive behavioral therapy (SMD 0.34, $95 \%$ CI $0.84-0.15$ ). Heterogeneity among the trials was moderate $\left(I^{2}=52 \%, q=0.13\right)$.

There are no known controlled trials for the treatment of BPD in MS. However, anecdotal reports suggest management with mood stabilizers (lithium, valproate, carbamazepine) and antipsychotics can be effective [170].

\section{Recommendations for Identification and Management of Mood Disorders}

Given the high prevalence and under-appreciation of psychiatric comorbidities in MS, it is recommended that MS healthcare providers routinely screen for mood disorders during clinic visits. Furthermore, the National MS Society has a navigator program to help connect patients with MS with providers in mental health. In addition, it is beneficial for neurology clinics to build a coalition with mental-health providers and teach them about the high prevalence of psychiatric comorbidities in the MS population. Treatment guidelines should follow those used in general practice for the treatment of depression, BPD, and anxiety. There is no evidence supporting the use of one psychotropic medication over another in the MS population.

\section{Stress Management}

There is also evidence that stress management reduces MRI markers of disease activity [171]. In 1 RCT, 121 people with relapsing forms of MS were randomized to receive stressmanagement therapy for MS (SMT-MS), consisting of a validated stress-management program with 16 individual therapy sessions, or control, in which participants continued their usual treatment but were provided a 5-h therapy workshop after study completion. SMT-MS resulted in a reduction in cumulative GdE and new T2 lesions ( $p=0.04$ and $p=0.005$, respectively). An increased proportion of participants remained free of GdE lesions and new T2 lesions during SMT-MS treatment versus control $[76.8 \%$ vs $54.7 \%(p=0.02)$ and $69.5 \%$ vs
$42.7 \%(p=0.006)]$. These effects were no longer detectable during the 24-week post-treatment follow-up period.

Along similar lines, 1 systematic review attempted to identify all RCTs assessing the influence of mindfulness training on the primary outcome of perceived stress [172]. Mindfulness training classically consists of instruction in 3 meditation techniques: breath awareness, body awareness, and dynamic yoga postures. For the purpose of the review, mindfulness training was required to include a core content of breath and body awareness and mindful movement. Only studies evaluating adult people with MS were included. Three studies were identified that met these requirements [173-175]. Only 1 trial demonstrated a low level of bias [175]. It investigated the effects of a mindfulness-based intervention (MBI) program on the outcomes of HRQoL, depression, and fatigue among adults with RRMS or SPMS [175]. In this trial, a total of 150 people were randomized either to the intervention or usual care. People were followed for 6 months, and attrition was low overall. Using an intent-totreat analysis, MBI improved all of the prespecified outcome measures versus usual care.

\section{Recommendations for Stress Management}

Several RCTs suggests a potential role for stress management that could include techniques such as mindfulness training in the management of MS. MBI can be recommended for those who express an interest, since it is safe and may be beneficial for HRQoL.

\section{Conclusion}

There is an increasing interest among patients, caregivers, and the scientific community in the use of lifestyle strategies to mitigate disease-related outcomes in MS. This interest comes, in part, from the growing recognition of the impact of comorbidities and lifestyle factors on disease activity, worsening of disability, chronic symptoms, and overall quality of life. Key observational studies now suggest an association between vascular comorbidities and an increased risk of disability and mortality. Depression, BPD, and anxiety are associated with poorer quality of life. There are several observational studies that show an inverse correlation between vitamin D levels and MRI markers of disease activity and worsening disability. Finally, multiple observational studies show an association between tobacco smoking and increased risk of disability and mortality.

The evidence for specific lifestyle interventions is more limited. A low-salt, low-fat, plant-based diet is recommended for the general population and may have added benefits for people with MS. More robust studies are required to clarify 
the role of dietary strategies in improving MS-related outcomes, and multiple RCTs are currently ongoing. Vitamin D3 supplementation is recommended to maintain $25(\mathrm{OH}) \mathrm{D}$ levels of $30 \mathrm{ng} / \mathrm{ml}$ or higher, consistent with most guidelines for the general population. Supplementation may have added benefits for people with MS, and multiple RCTs are underway to clarify the role of vitamin D3 supplementation as an adjunct treatment to DMTs. Exercise mitigates many MS-related symptoms, and likely has a role in maintenance of a healthy weight, although no weight management trials have been conducted to date. Smoking cessation decreases the risk of worsening disability in MS and should be encouraged in all patients with MS. Finally, given the under-recognition and under-treatment of psychiatric comorbidities in MS, regular screening is indicated with validated screening tests, where they exist. There is no evidence for any one treatment strategy over another in the MS population, so management of psychiatric comorbidities should follow general practice guidelines. Several RCTs also suggest a potential role for stress management in MS.

Altogether, the integration of lifestyle management with conventional medicine provides a multidimensional treatment approach to optimize overall health in individuals with MS. The impact of comorbidity treatment and lifestyle strategies deserves further investigation using larger studies across multiple regions to evaluate the impact of these interventions on disease-related outcomes on a more global scale.

Acknowledgments We thank Dr. Amy Sullivan, PsyD for her invaluable contribution on psychiatric comorbidities to the manuscript, which provided clarity and depth to our review on health and wellness in MS. Dr. Brandon Moss is supported by the National Multiple Sclerosis Society (NMSS) Institutional Clinician Training Award ICT 0002. Dr. Mary Rensel has received speaking and consulting fees from Biogen, Teva, Genzyme and Novartis. She receives grant funding from NMSS. Dr. Carrie Hersh has received speaking and consulting fees from Genzyme, Teva, Novartis, and Biogen. She receives grant funding from Genentech and Biogen.

Required Author Forms Disclosure forms provided by the authors are available with the online version of this article.

\section{References}

1. Dilokthornsakul P, Valuck RJ, Nair KV, Corboy JR, Allen RR, Campbell JD. Multiple sclerosis prevalence in the United States commercially insured population. Neurology 2016;86:1014-1021.

2. Browne P, Chandraratna D, Angood C, et al. Atlas of Multiple Sclerosis 2013: a growing global problem with widespread inequity. Neurology 2014;83:1022-1024.

3. Noseworthy JH, Lucchinetti C, Rodriguez M, Weinshenker BG. Multiple sclerosis. N Engl J Med 2000;343:938-952.

4. Hauser SL, Oksenberg JR. The neurobiology of multiple sclerosis: genes, inflammation, and neurodegeneration. Neuron 2006;52:6176.
5. Adelman G, Rane SG, Villa KF. The cost burden of multiple sclerosis in the United States: a systematic review of the literature. J Medical Econ 2013;16:639-647.

6. Gijsen R, Hoeymans N, Schellevis FG, Ruwaard D, Satariano WA, van den Bos GA. Causes and consequences of comorbidity: a review. J Clin Epidemiol 2001;54:661-674.

7. Marrie RA, Horwitz R, Cutter G, Tyry T, Campagnolo D, Vollmer T. Comorbidity delays diagnosis and increases disability at diagnosis in MS. Neurology 2009;72:117-124.

8. Marrie RA, Horwitz R, Cutter G, Tyry T. Cumulative impact of comorbidity on quality of life in MS. Acta Neurol Scand 2012;125:180-186.

9. Conway DS, Thompson NR, Cohen JA. Influence of hypertension, diabetes, hyperlipidemia, and obstructive lung disease on multiple sclerosis disease course. Mult Scler 2017; 23: 277-285.

10. Marrie RA, Elliott L, Marriott J, Cossoy M, Tennakoon A, Yu N. Comorbidity increases the risk of hospitalizations in multiple sclerosis. Neurology 2015;84:350-358.

11. Marrie RA, Horwitz RI, Cutter G, Tyry T, Vollmer T. Association between comorbidity and clinical characteristics of MS. Acta Neurol Scand 2011; 124: 135-141.

12. Wolff JL, Starfield B, Anderson G. Prevalence, expenditures, and complications of multiple chronic conditions in the elderly. Arch Intern Med 2002;162:2269-2276.

13. Rippe J. Lifestyle Medicine. New York: CRC Press; 2013.

14. Bell IR, Caspi O, Schwartz GE, et al. Integrative medicine and systemic outcomes research: issues in the emergence of a new model for primary health care. Arch Intern Med 2002;162:133140.

15. Snyderman R, Weil AT. Integrative medicine: bringing medicine back to its roots. Arch Intern Med 2002;162:395-397.

16. Neels JG, Olefsky JM. Inflamed fat: what starts the fire? J Clin Invest 2006;116:33-35.

17. Ouchi N, Parker JL, Lugus JJ, Walsh K. Adipokines in inflammation and metabolic disease. Nat Rev Immunol 2011;11:85-97.

18. De Rosa V, Procaccini C, Cali G, et al. A key role of leptin in the control of regulatory T cell proliferation. Immunity 2007;26:241255.

19. Pasare C, Medzhitov R. Toll pathway-dependent blockade of CD4 + CD25+ T cell-mediated suppression by dendritic cells. Science 2003;299:1033-1036.

20. Matarese G, Carrieri PB, La Cava A, et al. Leptin increase in multiple sclerosis associates with reduced number of CD4(+ )CD25+ regulatory T cells. Proc Natl Acad Sci U S A 2005;102: 5150-5155.

21. Marrie R, Horwitz R, Cutter G, Tyry T, Campagnolo D, Vollmer T. High frequency of adverse health behaviors in multiple sclerosis. Mult Scler 2009;15:105-113.

22. Pilutti LA, McAuley E, Motl RW. Weight status and disability in multiple sclerosis: An examination of bi-directional associations over a 24-month period. Mult Scler Relat Disord 2012;1:139-144.

23. Elgar FJ, Stewart JM. Validity of self-report screening for overweight and obesity. Evidence from the Canadian Community Health Survey. Can J Public Health 2008;99:423-427.

24. Pinhas-Hamiel O, Livne M, Harari G, Achiron A. Prevalence of overweight, obesity and metabolic syndrome components in multiple sclerosis patients with significant disability. Eur J Neurol 2015;22:1275-1279.

25. Wens I, Dalgas U, Stenager E, Eijnde BO. Risk factors related to cardiovascular diseases and the metabolic syndrome in multiple sclerosis - a systematic review. Mult Scler 2013;19:1556-1564.

26. Slawta JN, Wilcox AR, McCubbin JA, Nalle DJ, Fox SD, Anderson G. Health behaviors, body composition, and coronary heart disease risk in women with multiple sclerosis. Arch Phys Med Rehabil 2003;84:1823-1830. 
27. Lalmohamed A, Bazelier MT, Van Staa TP, et al. Causes of death in patients with multiple sclerosis and matched referent subjects: a population-based cohort study. Eur J Neurol 2012;19:1007-1014.

28. Lambert CP, Lee Archer R, Evans WJ. Body composition in ambulatory women with multiple sclerosis. Arch Phys Med Rehabil 2002;83:1559-1561.

29. Slawta JN, McCubbin JA, Wilcox AR, Fox SD, Nalle DJ, Anderson G. Coronary heart disease risk between active and inactive women with multiple sclerosis. Med Sci Sports Exerc 2002;34:905-912.

30. White LJ, McCoy SC, Castellano V, Ferguson MA, Hou W, Dressendorfer RH. Effect of resistance training on risk of coronary artery disease in women with multiple sclerosis. Scand J Clin Lab Invest 2006;66:351-355.

31. Mojtahedi MC, Snook EM, Motl RW, Evans EM. Bone health in ambulatory individuals with multiple sclerosis: impact of physical activity, glucocorticoid use, and body composition. J Rehabil Res Dev 2008;45:851-861.

32. Khurana SR, Bamer AM, Turner AP, et al. The prevalence of overweight and obesity in veterans with multiple sclerosis. Am J Phys Med Rehabil 2009;88:83-91.

33. Petajan JH, Gappmaier E, White AT, Spencer MK, Mino L, Hicks RW. Impact of aerobic training on fitness and quality of life in multiple sclerosis. Ann Neurol 1996;39:432-441.

34. Sioka C, Fotopoulos A, Georgiou A, et al. Body composition in ambulatory patients with multiple sclerosis. J Clin Densitom 2011;14:465-470.

35. Mahler A, Steiniger J, Bock M, et al. Is metabolic flexibility altered in multiple sclerosis patients? PLOS ONE 2012;7:e43675.

36. Kvistad SS, Myhr KM, Holmoy T, et al. Body mass index influence interferon-beta treatment response in multiple sclerosis. J Neuroimmunol 2015;288:92-97.

37. Tettey P, Simpson S, Jr., Taylor B, et al. Adverse lipid profile is not associated with relapse risk in MS: results from an observational cohort study. J Neurol Sci 2014;340:230-232.

38. Tettey P, Simpson S, Jr., Taylor B, et al. An adverse lipid profile is associated with disability and progression in disability, in people with MS. Mult Scler 2014;20:1737-1744.

39. Learmonth YC, Motl RW, Sandroff BM, Pula JH, Cadavid D. Validation of patient determined disease steps (PDDS) scale scores in persons with multiple sclerosis. BMC Neurol 2013;13:37.

40. Pilutti LA, Motl RW. Body mass index underestimates adiposity in persons with multiple sclerosis. Arch Phys Med Rehabil 2016;97:405-412.

41. Marrie RA, Reider N, Cohen J, et al. A systematic review of the incidence and prevalence of cardiac, cerebrovascular, and peripheral vascular disease in multiple sclerosis. Mult Scler 2015;21: 318-331.

42. Weinstock-Guttman B, Zivadinov R, Horakova D, et al. Lipid profiles are associated with lesion formation over 24 months in interferon-beta treated patients following the first demyelinating event. J Neurol Neurosurg Psychiatry 2013;84:1186-1191.

43. Kappus N, Weinstock-Guttman B, Hagemeier J, et al. Cardiovascular risk factors are associated with increased lesion burden and brain atrophy in multiple sclerosis. J Neurol Neurosurg Psychiatry 2016;87:181-187.

44. Marrie RA, Rudick R, Horwitz R, et al. Vascular comorbidity is associated with more rapid disability progression in multiple sclerosis. Neurology 2010;74:1041-1047.

45. Marrie RA, Cutter G, Tyry T. Substantial adverse association of visual and vascular comorbidities on visual disability in multiple sclerosis. Mult Scler 2011;17:1464-1471.

46. Kragt JJ, van der Linden FA, Nielsen JM, Uitdehaag BM, Polman $\mathrm{CH}$. Clinical impact of $20 \%$ worsening on Timed 25-foot Walk and 9-hole Peg Test in multiple sclerosis. Mult Scler 2006;12:594598
47. Schwartz CE, Vollmer T, Lee H. Reliability and validity of two self-report measures of impairment and disability for MS. North American Research Consortium on Multiple Sclerosis Outcomes Study Group. Neurology 1999;52:63-70.

48. Dagan A, Gringouz I, Kliers I, Segal G. Disability progression in multiple sclerosis is affected by the emergence of comorbid arterial hypertension. J Clin Neurol 2016;12:345-350.

49. Marrie RA, Elliott L, Marriott J, et al. Effect of comorbidity on mortality in multiple sclerosis. Neurology 2015;85:240-247.

50. Jick SS, Li L, Falcone GJ, Vassilev ZP, Wallander MA. Epidemiology of multiple sclerosis: results from a large observational study in the UK. J Neurol 2015;262:2033-2041.

51. Salter A, Tyry T, Wang G, Fox RJ, Cutter G, Marrie RA. Examining the joint effect of disability, health behaviors, and comorbidity on mortality in MS. Neurol Clin Pract 2016;6:397-408.

52. Koch-Henriksen N, Bronnum-Hansen H, Stenager E. Underlying cause of death in Danish patients with multiple sclerosis: results from the Danish Multiple Sclerosis Registry. J Neurol Neurosurg Psychiatry 1998;65:56-59.

53. Hirst C, Swingler R, Compston DA, Ben-Shlomo Y, Robertson NP. Survival and cause of death in multiple sclerosis: a prospective population-based study. J Neurol Neurosurg Psychiatry 2008;79: 1016-1021.

54. Wang JL, Reimer MA, Metz LM, Patten SB. Major depression and quality of life in individuals with multiple sclerosis. Int $\mathrm{J}$ Psychiatry Med 2000;30:309-317.

55. Janardhan V, Bakshi R. Quality of life in patients with multiple sclerosis: the impact of fatigue and depression. J Neurol Sci 2002;205:51-58.

56. Gulick EE. Correlates of quality of life among persons with multiple sclerosis. Nurs Res 1997;46:305-311.

57. Jonsson A, Dock J, Ravnborg MH. Quality of life as a measure of rehabilitation outcome in patients with multiple sclerosis. Acta Neurol Scand 1996;93:229-235.

58. Carta MG, Moro MF, Lorefice L, et al. Multiple sclerosis and bipolar disorders: the burden of comorbidity and its consequences on quality of life. J Affect Disord 2014;167:192-197.

59. Butler E, Matcham F, Chalder T. A systematic review of anxiety amongst people with Multiple Sclerosis. Mult Scler Relat Disord 2016;10:145-168.

60. Minden SL, Ding L, Cleary PD, et al. Improving the quality of mental health care in multiple sclerosis. J Neurol Sci 2013;335:4247.

61. Garcia J, Finlayson M. Mental health and mental health service use among people aged $45+$ with multiple sclerosis. Can J Commun Ment Health 2005;24:9-22.

62. Pompili M, Forte A, Palermo M, et al. Suicide risk in multiple sclerosis: a systematic review of current literature. J Psychosom Res 2012;73:411-417.

63. Kalson-Ray S, Edan G, Leray E, Group SS. An excessive risk of suicide may no longer be a reality for multiple sclerosis patients. Mult Scler 2017; 23: 864-871.

64. Kroenke K, Spitzer RL, Williams JB. The PHQ-9: validity of a brief depression severity measure. J Gen Intern Med 2001;16:606613.

65. Marrie RA, Reingold S, Cohen J, et al. The incidence and prevalence of psychiatric disorders in multiple sclerosis: a systematic review. Mult Scler 2015;21:305-317.

66. Marrie RA, Fisk JD, Yu BN, et al. Mental comorbidity and multiple sclerosis: validating administrative data to support population-based surveillance. BMC Neurol 2013;13:16.

67. Rao SM, Leo GJ, Bernardin L, Unverzagt F. Cognitive dysfunction in multiple sclerosis. I. Frequency, patterns, and prediction. Neurology 1991;41:685-691. 
68. Gilchrist AC, Creed FH. Depression, cognitive impairment and social stress in multiple sclerosis. J Psychosom Res 1994;38: 193-201.

69. Arnett PA, Higginson CI, Voss WD, et al. Depressed mood in multiple sclerosis: relationship to capacity-demanding memory and attentional functioning. Neuropsychology 1999;13:434-446.

70. Mohr DC, Goodkin DE, Likosky W, Gatto N, Baumann KA, Rudick RA. Treatment of depression improves adherence to interferon beta-1b therapy for multiple sclerosis. Arch Neurol 1997;54: 531-533.

71. Burns MN, Nawacki E, Siddique J, Pelletier D, Mohr DC. Prospective examination of anxiety and depression before and during confirmed and pseudoexacerbations in patients with multiple sclerosis. Psychosom Med 2013;75:76-82.

72. Mohr DC, Goodkin DE, Bacchetti P, et al. Psychological stress and the subsequent appearance of new brain MRI lesions in MS. Neurology 2000;55:55-61.

73. Christakos S, Dhawan P, Liu Y, Peng X, Porta A. New insights into the mechanisms of vitamin D action. J Cell Biochem 2003;88: 695-705.

74. DeLuca HF. Overview of general physiologic features and functions of vitamin D. Am J Clin Nutr 2004;80:1689S-1696S.

75. Sutton AL, MacDonald PN. Vitamin D: more than a "bone-a-fide" hormone. Mol Endocrinol 2003;17:777-791.

76. Bhalla AK, Amento EP, Clemens TL, Holick MF, Krane SM. Specific high-affinity receptors for 1,25-dihydroxyvitamin D3 in human peripheral blood mononuclear cells: presence in monocytes and induction in $\mathrm{T}$ lymphocytes following activation. $\mathrm{J}$ Clin Endocrinol Metab 1983;57:1308-1310.

77. Provvedini DM, Tsoukas CD, Deftos LJ, Manolagas SC. 1,25dihydroxyvitamin D3 receptors in human leukocytes. Science 1983;221:1181-1183.

78. Liu PT, Stenger S, Li H, et al. Toll-like receptor triggering of a vitamin D-mediated human antimicrobial response. Science 2006;311:1770-1773.

79. Veldman CM, Cantorna MT, DeLuca HF. Expression of 1,25dihydroxyvitamin $\mathrm{D}(3)$ receptor in the immune system. Arch Biochem Biophys 2000;374:334-338.

80. Rigby WF, Denome S, Fanger MW. Regulation of lymphokine production and human $\mathrm{T}$ lymphocyte activation by 1,25 dihydroxyvitamin D3. Specific inhibition at the level of messenger RNA. J Clin Invest 1987;79:1659-1664.

81. Rigby WF, Noelle RJ, Krause K, Fanger MW. The effects of 1,25dihydroxyvitamin $\mathrm{D} 3$ on human $\mathrm{T}$ lymphocyte activation and proliferation: a cell cycle analysis. J Immunol 1985;135:2279-2286.

82. Tsoukas CD, Provvedini DM, Manolagas SC. 1,25dihydroxyvitamin D3: a novel immunoregulatory hormone. Science 1984;224:1438-1440.

83. Bruce D, Yu S, Ooi JH, Cantorna MT. Converging pathways lead to overproduction of IL-17 in the absence of vitamin D signaling. Int Immunol 2011;23:519-528.

84. Chang SH, Chung Y, Dong C. Vitamin D suppresses Th17 cytokine production by inducing $\mathrm{C} / \mathrm{EBP}$ homologous protein $(\mathrm{CHOP})$ expression. J Biol Chem 2010;285:38751-38755.

85. Colin EM, Asmawidjaja PS, van Hamburg JP, et al. 1,25dihydroxyvitamin D3 modulates Th17 polarization and interleukin-22 expression by memory $\mathrm{T}$ cells from patients with early rheumatoid arthritis. Arthritis Rheum 2010;62:132-142.

86. Tang J, Zhou R, Luger D, et al. Calcitriol suppresses antiretinal autoimmunity through inhibitory effects on the Th17 effector response. J Immunol 2009;182:4624-4632.

87. Adorini L, Penna G. Dendritic cell tolerogenicity: a key mechanism in immunomodulation by vitamin D receptor agonists. Hum Immunol 2009;70:345-352.

88. Correale J, Ysrraelit MC, Gaitan MI. Immunomodulatory effects of Vitamin D in multiple sclerosis. Brain 2009;132:1146-1160.
89. Soilu-Hanninen M, Airas L, Mononen I, Heikkila A, Viljanen M, Hanninen A. 25-Hydroxyvitamin D levels in serum at the onset of multiple sclerosis. Mult Scler 2005;11:266-271.

90. Smolders J, Menheere P, Kessels A, Damoiseaux J, Hupperts R. Association of vitamin D metabolite levels with relapse rate and disability in multiple sclerosis. Mult Scler 2008;14:1220-1224.

91. van der Mei IA, Ponsonby AL, Dwyer T, et al. Vitamin D levels in people with multiple sclerosis and community controls in Tasmania, Australia. J Neurol 2007;254:581-590.

92. Mowry EM, Waubant E, McCulloch CE, et al. Vitamin D status predicts new brain magnetic resonance imaging activity in multiple sclerosis. Ann Neurol 2012;72:234-240.

93. Fitzgerald KC, Munger KL, Kochert K, et al. Association of vitamin $\mathrm{D}$ levels with multiple sclerosis activity and progression in patients receiving interferon beta-1b. JAMA Neurol 2015;72: 1458-1465.

94. Ascherio A, Munger KL, White R, et al. Vitamin D as an early predictor of multiple sclerosis activity and progression. JAMA Neurol 2014;71:306-314.

95. Burton JM, Kimball S, Vieth R, et al. A phase I/II dose-escalation trial of vitamin D3 and calcium in multiple sclerosis. Neurology 2010;74:1852-1859.

96. Kampman MT, Steffensen LH, Mellgren SI, Jorgensen L. Effect of vitamin D3 supplementation on relapses, disease progression, and measures of function in persons with multiple sclerosis: exploratory outcomes from a double-blind randomised controlled trial. Mult Scler 2012;18:1144-1151.

97. Soilu-Hanninen M, Aivo J, Lindstrom BM, et al. A randomised, double blind, placebo controlled trial with vitamin D3 as an add on treatment to interferon beta- $1 \mathrm{~b}$ in patients with multiple sclerosis. J Neurol Neurosurg Psychiatry 2012;83:565-571.

98. Sotirchos ES, Bhargava P, Eckstein C, et al. Safety and immunologic effects of high- $v s$ low-dose cholecalciferol in multiple sclerosis. Neurology 2016;86:382-390.

99. Stein MS, Liu Y, Gray OM, et al. A randomized trial of high-dose vitamin D2 in relapsing-remitting multiple sclerosis. Neurology 2011;77:1611-1618.

100. Wingerchuk DM, Lesaux J, Rice GP, Kremenchutzky M, Ebers GC. A pilot study of oral calcitriol (1,25-dihydroxyvitamin D3) for relapsing-remitting multiple sclerosis. J Neurol Neurosurg Psychiatry 2005;76:1294-1296.

101. Smolders J, Hupperts R, Barkhof F, et al. Efficacy of vitamin D3 as add-on therapy in patients with relapsing-remitting multiple sclerosis receiving subcutaneous interferon beta-1a: a Phase II, multicenter, double-blind, randomized, placebo-controlled trial. J Neurol Sci 2011;311:44-49.

102. Dorr J, Ohlraun S, Skarabis H, Paul F. Efficacy of vitamin D supplementation in multiple sclerosis (EVIDIMS Trial): study protocol for a randomized controlled trial. Trials 2012;13:15.

103. Bhargava P, Cassard S, Steele SU, et al. The vitamin D to ameliorate multiple sclerosis (VIDAMS) trial: study design for a multicenter, randomized, double-blind controlled trial of vitamin D in multiple sclerosis. Contemp Clin Trials 2014;39:288-293.

104. Talhout R, Schulz T, Florek E, van Benthem J, Wester P, Opperhuizen A. Hazardous compounds in tobacco smoke. Int J Environ Res Public Health 2011;8:613-628.

105. Bedoya SK, Lam B, Lau K, Larkin J, 3rd. Th17 cells in immunity and autoimmunity. Clin Dev Immunol 2013;2013:986789.

106. Denison MS, Nagy SR. Activation of the aryl hydrocarbon receptor by structurally diverse exogenous and endogenous chemicals. Annu Rev Pharmacol Toxicol 2003;43:309-334.

107. Veldhoen M, Hirota K, Westendorf AM, et al. The aryl hydrocarbon receptor links TH17-cell-mediated autoimmunity to environmental toxins. Nature 2008;453:106-109.

108. Duarte JH, Di Meglio P, Hirota K, Ahlfors H, Stockinger B. Differential influences of the aryl hydrocarbon receptor on Th17 
mediated responses in vitro and in vivo. PLOS ONE 2013;8: e79819.

109. D'Hooghe M B, Haentjens P, Nagels G, De Keyser J. Alcohol, coffee, fish, smoking and disease progression in multiple sclerosis. Eur J Neurol 2012;19:616-624.

110. Di Pauli F, Reindl M, Ehling R, et al. Smoking is a risk factor for early conversion to clinically definite multiple sclerosis. Mult Scler 2008;14:1026-1030.

111. Healy BC, Ali EN, Guttmann CR, et al. Smoking and disease progression in multiple sclerosis. Arch Neurol 2009;66:858-864.

112. Hernan MA, Jick SS, Logroscino G, Olek MJ, Ascherio A, Jick H. Cigarette smoking and the progression of multiple sclerosis. Brain 2005;128:1461-1465.

113. Koch M, van Harten A, Uyttenboogaart M, De Keyser J. Cigarette smoking and progression in multiple sclerosis. Neurology 2007;69:1515-1520.

114. Manouchehrinia A, Tench CR, Maxted J, Bibani RH, Britton J, Constantinescu CS. Tobacco smoking and disability progression in multiple sclerosis: United Kingdom cohort study. Brain 2013;136:2298-2304

115. Roudbari SA, Ansar MM, Yousefzad A. Smoking as a risk factor for development of Secondary Progressive Multiple Sclerosis: a study in IRAN, Guilan. J Neurol Sci 2013;330:52-55.

116. Handel AE, Williamson AJ, Disanto G, Dobson R, Giovannoni G, Ramagopalan SV. Smoking and multiple sclerosis: an updated meta-analysis. PLOS ONE 2011;6:e16149.

117. Ramanujam R, Hedstrom AK, Manouchehrinia A, et al. Effect of smoking cessation on multiple sclerosis prognosis. JAMA Neurol 2015;72:1117-1123.

118. O'Gorman CM, Broadley SA. Smoking increases the risk of progression in multiple sclerosis: A cohort study in Queensland, Australia. J Neurol Sci 2016;370:219-223.

119. Bronnum-Hansen H, Koch-Henriksen N, Stenager E. Trends in survival and cause of death in Danish patients with multiple sclerosis. Brain 2004;127:844-850.

120. Jick SS, Li L, Falcone GJ, Vassilev ZP, Wallander MA. Mortality of patients with multiple sclerosis: a cohort study in UK primary care. J Neurol 2014;261:1508-1517.

121. Manouchehrinia A, Weston M, Tench CR, Britton J, Constantinescu CS. Tobacco smoking and excess mortality in multiple sclerosis: a cohort study. J Neurol Neurosurg Psychiatry 2014;85:1091-1095.

122. Scalfari A, Knappertz V, Cutter G, Goodin DS, Ashton R, Ebers GC. Mortality in patients with multiple sclerosis. Neurology 2013;81:184-192.

123. Turner AP, Hartoonian N, Maynard C, Leipertz SL, Haselkorn JK. Smoking and physical activity: examining health behaviors and 15 -year mortality among individuals with multiple sclerosis. Arch Phys Med Rehabil 2015;96:402-409.

124. Holick MF, Binkley NC, Bischoff-Ferrari HA, et al. Evaluation, treatment, and prevention of vitamin D deficiency: an Endocrine Society clinical practice guideline. J Clin Endocrinol Metab 2011;96:1911-1930.

125. Dawson-Hughes B, Mithal A, Bonjour JP, et al. IOF position statement: vitamin D recommendations for older adults. Osteoporos Int 2010;21:1151-1154.

126. American Geriatrics Society Workgroup on Vitamin D Supplementation for Older Adults. Recommendations abstracted from the American Geriatrics Society Consensus Statement on vitamin D for Prevention of Falls and Their Consequences. J Am Geriatr Soc 2014;62:147-152.

127. Dawson-Hughes B, Harris SS, Krall EA, Dallal GE. Effect of calcium and vitamin D supplementation on bone density in men and women 65 years of age or older. N Engl J Med 1997;337:670676
128. Chapuy MC, Pamphile R, Paris E, et al. Combined calcium and vitamin D3 supplementation in elderly women: confirmation of reversal of secondary hyperparathyroidism and hip fracture risk: the Decalyos II study. Osteoporos Int 2002;13:257-264.

129. Trivedi DP, Doll R, Khaw KT. Effect of four monthly oral vitamin D3 (cholecalciferol) supplementation on fractures and mortality in men and women living in the community: randomised double blind controlled trial. BMJ 2003;326:469.

130. Sanders KM, Stuart AL, Williamson EJ, et al. Annual high-dose oral vitamin D and falls and fractures in older women: a randomized controlled trial. JAMA 2010;303:1815-1822.

131. Ross AC, Manson JE, Abrams SA, et al. The 2011 report on dietary reference intakes for calcium and vitamin D from the Institute of Medicine: what clinicians need to know. J Clin Endocrinol Metab 2011;96:53-58.

132. Heaney RP. Vitamin D: criteria for safety and efficacy. Nutr Rev 2008;66:S178-S181.

133. Houghton LA, Vieth R. The case against ergocalciferol (vitamin D2) as a vitamin supplement. Am J Clin Nutr 2006;84:694-697.

134. Mazahery H, von Hurst PR. Factors Affecting 25-Hydroxyvitamin $\mathrm{D}$ concentration in response to vitamin D supplementation. Nutrients 2015;7:5111-5142.

135. Vieth R, Chan PC, MacFarlane GD. Efficacy and safety of vitamin D3 intake exceeding the lowest observed adverse effect level. Am J Clin Nutr 2001;73:288-294.

136. Smolders J, Peelen E, Thewissen M, et al. Safety and T cell modulating effects of high dose vitamin D3 supplementation in multiple sclerosis. PLOS ONE 2010;5:e15235.

137. Stead LF, Koilpillai P, Fanshawe TR, Lancaster T. Combined pharmacotherapy and behavioural interventions for smoking cessation. Cochrane Database Syst Rev 2016;3:CD008286.

138. Cahill K, Stevens S, Perera R, Lancaster T. Pharmacological interventions for smoking cessation: an overview and network metaanalysis. Cochrane Database Syst Rev 2013:CD009329.

139. Chang PH, Chiang CH, Ho WC, Wu PZ, Tsai JS, Guo FR. Combination therapy of varenicline with nicotine replacement therapy is better than varenicline alone: a systematic review and meta-analysis of randomized controlled trials. BMC Public Health 2015;15:689.

140. Stamler J. Toward a modern Mediterranean diet for the 21st century. Nutr Metab Cardiovasc Dis 2013;23:1159-1162.

141. McGuire S. Scientific Report of the 2015 Dietary Guidelines Advisory Committee. Washington, DC: US Departments of Agriculture and Health and Human Services, 2015. Adv Nutr 2016;7:202-204

142. Masullo L, Papas MA, Cotugna N, Baker S, Mahoney L, Trabulsi J. Complementary and alternative medicine use and nutrient intake among individuals with multiple sclerosis in the United States. J Community Health 2015;40:153-160.

143. Wahls TL, Adamson E. The Wahls protocol cooking for life : the revolutionary modern Paleo plan to treat all chronic autoimmune conditions. New York: Avery; 2017.

144. Swank RL. Multiple sclerosis: twenty years on low fat diet. Arch Neurol 1970;23:460-474.

145. Varady KA, Hellerstein MK. Alternate-day fasting and chronic disease prevention: a review of human and animal trials. Am J Clin Nutr 2007;86:7-13

146. Yadav V, Marracci G, Kim E, et al. Low-fat, plant-based diet in multiple sclerosis: A randomized controlled trial. Mult Scler Relat Disord 2016;9:80-90.

147. Farez MF, Fiol MP, Gaitan MI, Quintana FJ, Correale J. Sodium intake is associated with increased disease activity in multiple sclerosis. J Neurol Neurosurg Psychiatry 2015;86:26-31 
148. Saadatnia M, Etemadifar M, Fatehi F, et al. Short-term effects of prolonged fasting on multiple sclerosis. Eur Neurol 2009;61:230232.

149. Bisht B, Darling WG, Grossmann RE, et al. A multimodal intervention for patients with secondary progressive multiple sclerosis: feasibility and effect on fatigue. J Altern Complement Med 2014;20:347-355.

150. Dietary Guidelines for Americans 2015-2020. Available at: http:// health.gov/dietaryguidelines/2015/guidelines/. Accessed July 31, 2017.

151. Motl RW, Sandroff BM. Benefits of exercise training in multiple sclerosis. Curr Neurol Neurosci Rep 2015;15:62.

152. Pilutti LA, Platta ME, Motl RW, Latimer-Cheung AE. The safety of exercise training in multiple sclerosis: a systematic review. $\mathrm{J}$ Neurol Sci 2014;343:3-7.

153. Pearson M, Dieberg G, Smart N. Exercise as a therapy for improvement of walking ability in adults with multiple sclerosis: a meta-analysis. Arch Phys Med Rehabil 2015;96:1339-1348.

154. Podsiadlo D, Richardson S. The timed "Up \& Go": a test of basic functional mobility for frail elderly persons. J Am Geriatr Soc 1991;39:142-148.

155. Gunn H, Markevics S, Haas B, Marsden J, Freeman J. Systematic review: the effectiveness of interventions to reduce falls and improve balance in adults with multiple sclerosis. Arch Phys Med Rehabil 2015;96:1898-1912.

156. Heine M, van de Port I, Rietberg MB, van Wegen EE, Kwakkel G. Exercise therapy for fatigue in multiple sclerosis. Cochrane Database Syst Rev 2015:CD009956.

157. Sandroff BM, Motl RW, Scudder MR, DeLuca J. Systematic, Evidence-based review of exercise, physical activity, and physical fitness effects on cognition in persons with multiple sclerosis. Neuropsychol Rev 2016;26:271-294.

158. Sandroff BM, Johnson CL, Motl RW. Exercise training effects on memory and hippocampal viscoelasticity in multiple sclerosis: a novel application of magnetic resonance elastography. Neuroradiology 2017;59:61-67.

159. Amatya B, Khan F, La Mantia L, Demetrios M, Wade DT. Non pharmacological interventions for spasticity in multiple sclerosis. Cochrane Database Syst Rev 2013:CD009974.

160. Cramer H, Lauche R, Azizi H, Dobos G, Langhorst J. Yoga for multiple sclerosis: a systematic review and meta-analysis. PLOS ONE 2014;9:e112414.

161. Multiple Sclerosis: NCHPAD - Building Inclusive Communities. www.nchpad.org/70/527/Multiple Sclerosis. Accessed On: 8/4/17
162. Fiest KM, Walker JR, Bernstein CN, et al. Systematic review and meta-analysis of interventions for depression and anxiety in persons with multiple sclerosis. Mult Scler Relat Disord 2016;5:1226.

163. Ehde DM, Kraft GH, Chwastiak L, et al. Efficacy of paroxetine in treating major depressive disorder in persons with multiple sclerosis. Gen Hosp Psychiatry 2008;30:40-48.

164. Mohr DC, Boudewyn AC, Goodkin DE, Bostrom A, Epstein L. Comparative outcomes for individual cognitive-behavior therapy, supportive-expressive group psychotherapy, and sertraline for the treatment of depression in multiple sclerosis. J Consult Clin Psychol 2001;69:942-949.

165. Schiffer RB, Wineman NM. Antidepressant pharmacotherapy of depression associated with multiple sclerosis. Am J Psychiatry 1990;147:1493-1497.

166. Solaro C, Bergamaschi R, Rezzani C, et al. Duloxetine is effective in treating depression in multiple sclerosis patients: an open-label multicenter study. Clin Neuropharmacol 2013;36:114-116.

167. Shafey $\mathrm{H}$. The effect of fluoxetine in depression associated with multiple sclerosis. Can J Psychiatry 1992;37:147-148.

168. Scott TF, Nussbaum P, McConnell H, Brill P. Measurement of treatment response to sertraline in depressed multiple sclerosis patients using the Carroll scale. Neurol Res 1995;17:421-422.

169. Dean G. A double-blind trial with an antidepressant drug, imipramine, in multiple sclerosis. S Afr Med J 1969;43:86-87.

170. Paparrigopoulos T, Ferentinos P, Kouzoupis A, Koutsis G, Papadimitriou GN. The neuropsychiatry of multiple sclerosis: focus on disorders of mood, affect and behaviour. Int Rev Psychiatry 2010;22:14-21.

171. Mohr DC, Lovera J, Brown T, et al. A randomized trial of stress management for the prevention of new brain lesions in MS. Neurology 2012;79:412-419.

172. Simpson R, Booth J, Lawrence M, Byrne S, Mair F, Mercer S. Mindfulness based interventions in multiple sclerosis-a systematic review. BMC Neurol 2014;14:15.

173. Mills N, Allen J. Mindfulness of movement as a coping strategy in multiple sclerosis. A pilot study. Gen Hosp Psychiatry 2000;22: 425-431.

174. Tavee J, Rensel M, Planchon SM, Butler RS, Stone L. Effects of meditation on pain and quality of life in multiple sclerosis and peripheral neuropathy: a pilot study. Int J MS Care 2011;13:163168.

175. Grossman P, Kappos L, Gensicke H, et al. MS quality of life, depression, and fatigue improve after mindfulness training: a randomized trial. Neurology 2010;75:1141-1149. 